\title{
Seasonal Asymmetries in the Lag between Insolation and Surface Temperature
}

\author{
AARON DONOHOE \\ Polar Science Center, Applied Physics Laboratory, University of Washington, Seattle, Washington \\ ELIZA DAWSON \\ Stanford University, Palo Alto, California
}

LYNN MCMURDIE AND DAVID S. BATTISTI

Department of Atmospheric Sciences, University of Washington, Seattle, Washington

ANDY RHINES

Netflix, Los Gatos, California

(Manuscript received 6 May 2019, in final form 5 January 2020)

\begin{abstract}
We analyze the temporal structure of the climatological seasonal cycle in surface air temperature across the globe. We find that, over large regions of Earth, the seasonal cycle of surface temperature departs from an annual harmonic: the duration of fall and spring differ by as much as 2 months. We characterize this asymmetry by the metric ASYM, defined as the phase lag of the seasonal maximum temperature relative to the summer solstice minus the phase lag of the seasonal minimum temperature relative to winter solstice. We present a global analysis of ASYM from weather station data and atmospheric reanalysis and find that ASYM is well represented in the reanalysis. ASYM generally features positive values over land and negative values over the ocean, indicating that spring has a longer duration over the land domain whereas fall has a longer duration over the ocean. However, ASYM also features more positive values over North America compared to Europe and negative values in the polar regions over ice sheets and sea ice. Understanding the root cause of the climatological ASYM will potentially further our understanding of controls on the seasonal cycle of temperature and its future/past changes. We explore several candidate mechanisms to explain the spatial structure of ASYM including 1) modification of the seasonal cycle of surface solar radiation by the seasonal evolution of cloud thickness, 2) differences in the seasonal cycle of the atmospheric boundary layer depth over ocean and over land, and 3) temperature advection by the seasonally evolving atmospheric circulation.
\end{abstract}

\section{Introduction}

The climatological seasonal cycle of surface $(2 \mathrm{~m})$ daily average air temperature (hereafter $T_{2 \mathrm{~m}}$ ) in the extratropics is forced by the seasonal cycle of insolation and moderated by atmospheric advection and radiative damping (North and Coakley 1978; Donohoe and Battisti 2013). Throughout the extratropics, seasonal variations in insolation are nearly sinusoidal (Berger 1978). Hence, the seasonal cycle of $T_{2 \mathrm{~m}}$ is well represented by the amplitude and phase of the annual harmonic (Wallace and Osborn 2002; Thomson 1995; McKinnon et al. 2013). The spatial structure of the

Corresponding author: Aaron Donohoe, adonohoe@u.washington.edu amplitude and phase of the annual harmonic in $T_{2 \mathrm{~m}}$ provide insights into the underlying climate processes including the following:

- the large amplitude of $T_{2 \mathrm{~m}}$ in the high latitudes driven by the large magnitude of seasonal variations in insolation (Von Hann 1903; Peixoto and Oort 1992);

- the small amplitude and large phase lag in $T_{2 \mathrm{~m}}$ over the oceans due to the high heat capacity of the ocean mixed layer and the efficient thermal coupling between $T_{2 \mathrm{~m}}$ and sea surface temperature (SST; Prescott and Collins 1951); and

Publisher's Note: This article was revised on 10 April 2020 to replace Figs. 2 and A2, which were processed at a lower resolution when originally published. 
- the large amplitude and small phase lag of $T_{2 \mathrm{~m}}$ over continental regions far downwind of the ocean due to the small heat capacity of the land surface and the atmospheric boundary layer relative to that of the ocean mixed layer (Brooks 1917).

In addition, continental regions that are downwind of the ocean represent a mixture of the phase and amplitude of $T_{2 \mathrm{~m}}$ between the abovementioned marine and continental cases (Stine et al. 2009).

Additional insights into the processes driving the seasonal cycle have been gleaned from the spatial patterns of the change in the phase and amplitude of the annual harmonic of $T_{2 \mathrm{~m}}$ and atmospheric temperature due to global warming that include the following:

- reduced amplitude and delayed phase of $T_{2 \mathrm{~m}}$ in regions where sea ice melt exposes the atmosphere to the thermal reservoir of the ocean (Dwyer et al. 2012);

- enhanced amplitude and reduced phase lag of midtropospheric temperature (Donohoe et al. 2014) due to enhanced shortwave absorption in the atmospheric column associated with atmospheric moistening (Donohoe and Battisti 2013); and

- phase changes in $T_{2 \mathrm{~m}}$ over land moderated by the strength of mixing between marine and continental air associated with annular mode changes (Stine and Huybers 2012).

Finally, the spatial pattern of observed changes in the annular harmonic of $T_{2 \mathrm{~m}}$ provide a detectable fingerprint of anthropogenic forcing (Santer et al. 2018).

Are there additional insights to be gleaned from the climatological seasonal cycle in $T_{2 \mathrm{~m}}$ that extend beyond the amplitude and phase of the annual harmonic? For example, Is the cooling of the surface air temperature in the fall more rapid than the warming in the spring? Is the answer the same over the ocean and land domains or between the different continents? Annual harmonic analysis is poorly suited to answer these questions because the cold and warm seasons are constructed to be symmetric in amplitude, duration and timing.

For illustrative purposes, consider the seasonal cycle of $T_{2 \mathrm{~m}}$ at Seattle-Tacoma International Airport (SEATAC; Fig. 1) that inspired this work-due in part to the authors' familiarity with this region. The minimum temperature of the smoothed seasonal cycle (see methods in section $2 \mathrm{~b}$ ) occurs on 4 January, 14 days after the winter solstice (the timing of the $T_{2 \mathrm{~m}}$ extrema and solstices are shown by the vertical black and red lines, respectively) whereas the maximum temperature occurs on 4 August, 44 days after the summer solstice. This (30 day) seasonal asymmetry of the temperature lag (hereafter ASYM) relative to insolation suggests that the seasonal warming into the peak of summer takes almost 2 months longer than the seasonal cooling into the peak of winter. This point is visualized by comparing the observed seasonal cycle of $T_{2 \mathrm{~m}}$ to an annual harmonic fit to the data (cf. the thick black line to the thick dashed blue line in Fig. 1). The rate of cooling (warming) during the autumn (spring) is far greater (less) than that expected from the annual harmonic. The annual harmonic analysis of $T_{2 \mathrm{~m}}$ cannot capture these substantial seasonal timing asymmetries and instead produces a phase of temperature that splits the differences between the phase of the maximum and minimum.

Departures of $T_{2 \mathrm{~m}}$ from the annual harmonic that are characterized by ASYM have received little attention in the literature but have the potential to provide new insights into the physics of climate and its future changes. Van den Broeke (1998) note that $T_{2 \mathrm{~m}}$ over Antarctica has a significant semiannual component with a slow cooling of temperatures during the winter and fast warming during the spring. This seasonality is understood to result from the seasonal "shape" of insolation, which follows the top half of a sine curve in the summer but flat-lines to zero during winter and thus projects onto the higher-order harmonics via Gibbs overshoot. May et al. (1992) produced a global analysis of $T_{2 \mathrm{~m}}$ at 122 stations including the (separate) timing of the seasonal maximum and minimum temperature during the smoothed seasonal cycle (see their Figs. 89 and 91). They noted that $T_{2 \mathrm{~m}}$ departs from the annual harmonic in monsoonal regions where the onset of the monsoons initiates cooling prior to the summer solstice (Hurley and Boos 2015) but commented little on the large-scale patterns of ASYM. More recently, Dodds et al. (2016) analyzed the timing of minimum and maximum temperatures at weather stations in the United States as well as trends in the seasonal timing over the duration of the observational record.

The purpose of this manuscript is threefold: 1) to present a comprehensive global analysis of the climatological ASYM from historic station observations; 2) to establish that the ASYM in observations is captured in the ERA-Interim product and use the latter product to document the global three-dimensional structure of ASYM (including the seasonal cycle of temperature in the troposphere above the boundary layer); and 3) to explore possible physical mechanisms that govern the global structure of ASYM.

\section{Data and methods}

\section{a. Datasets}

\section{1) STATION DATA}

Historical station data of near-surface $(2 \mathrm{~m})$ air temperature from the Global Historical Climatology Network (GHCN; Peterson and Vose 1997) are the primary source of data used in our analysis. This dataset has 
daily maximum $T_{\mathrm{MAX}}$ and minimum temperature $T_{\mathrm{MIN}}$ for nearly 100000 stations with some stations reporting nearly continuous data for 175 years and others containing less than 1 year of data. We thin the number of stations used in our analysis using the following criteria: 1 ) for stations within $0.1^{\circ}$ (latitude and longitude) of each other, we remove all data except the longest continuous record-this eliminates locations that have registered secondary or tertiary data; 2) stations with less then 20 years of data are eliminated; 3) stations that have less than 5 years of data on any calendar day are eliminated; and 4) stations equatorward of $25^{\circ}$ latitude for which the seasonal cycle is small in magnitude and more semiannual in nature are eliminated. These criteria reduce the number of stations to 3096 stations dispersed globally across land areas. We analyze the seasonal cycle of $T_{2 \mathrm{~m}}$, which is defined as the average of $T_{\text {MAX }}$ and $T_{\text {MIN }}$. While this method of averaging is biased relative to true time averages, it is recommended for the sake of consistency when comparing historical datasets such as station observations that often only provide daily extrema (World Meteorological Organization 2011). All results presented here are nearly unchanged if we analyze the seasonal timing of $T_{\mathrm{MAX}}$ or $T_{\mathrm{MIN}}$ in isolation.

ASYM is also calculated from in situ $T_{2 \mathrm{~m}}$ [and sea surface temperature (SST)] data at marine stations. Marine observations come from ccean weather ships that were deployed in the World War II era by the United Kingdom (Downes 1977) and the United States (U.S. Weather Bureau 1977) at fixed locations primarily in the North Atlantic but secondarily in the North Pacific. The $T_{2 \mathrm{~m}}$ and SST records of sufficient length to define a smoothed climatological seasonal cycle were retrieved from stations Alpha, Bravo, Charlie, Delta, Echo, India, Juliet, Kilo, and Mike in the Atlantic, and stations Extra, Hotel, Nan, Papa (Belka et al. 2014), and Victor in the Pacific.

Additionally, in situ data from Washington state are used to analyze the seasonal timing of temperature and surface solar radiation. ASYM is calculated from nearsurface air temperature data from Mount Rainier (D’Amico 2019), Washington, (Paradise Ranger Station, altitude: $1646 \mathrm{~m}$, and Camp Muir climbing camp, altitude: $3105 \mathrm{~m}$ ). Finally, we also examine the seasonal cycle of total, direct, and diffuse solar radiation measured on the roof of the Department of Atmospheric Sciences at the University of Washington in Seattle, approximately 15 miles from SEATAC airport (there are no solar data at SEATAC); these data have been measured at 1-min intervals since 2000.

\section{2) GRIDDED TEMPERATURE DATA}

While our primary focus here is on ASYM derived from historical observations, we demonstrate that the regional structure of ASYM seen in the station data is well represented in the reanalysis data which allows for a spatially continuous global analysis of ASYM. We consider two sets of daily reanalysis temperature data: the ERA-Interim (Dee et al. 2011) 2-m air temperature at a resolution of $1.5^{\circ}$ latitude (or roughly $150 \mathrm{~km}$ ), and the NCEP reanalysis 2-m air temperature at a resolution of $2^{\circ}$ latitude (or roughly $200 \mathrm{~km}$ ). Results using the higher-resolution ERA data are shown in the manuscript figures; results using NCEP are shown in the appendix (Fig. A2). The ERA product we use spans the time period 1979-2015 and the NCEP data span 19702012. The primary conclusions are insensitive to the choice of reanalysis product.

In some instances, geographic features that are smaller than the ERA-Interim gridbox can introduce differences between the seasonal cycle of $T_{2 \mathrm{~m}}$ (and potentially ASYM) measured at stations and its representation at the nearest ERA-Interim gridbox. For example, shown in the bottom panel of Fig. 1 is the $T_{2 \mathrm{~m}}$ from the Seattle station data (SEATAC) and the temperature from the ERA gridbox that includes Seattle. The temporal "shape" of the seasonal evolution of $T_{2 \mathrm{~m}}$ and the timing of the maximum and minimum are nearly identical in the ERA and station data (cf. the vertical blue and black lines that are nearly on top of each other). However, in absolute terms, the $T_{2 \mathrm{~m}}$ at the nearest-neighbor ERA gridbox is approximately $2.5^{\circ} \mathrm{F}\left(1.4^{\circ} \mathrm{C}\right)$ colder than that measured at SEATAC throughout the year. This absolute mismatch should be expected from the approximately $150-\mathrm{km}$ horizontal resolution of the ERA data because the gridbox that includes Seattle also extends across the Cascade mountains into central Washington. Thus, the ERA gridbox that includes Seattle also includes the town of Ellensburg, Washington, located east of the Cascades. The February average minimum temperature is $19^{\circ} \mathrm{F}$ $\left(-7^{\circ} \mathrm{C}\right)$ in Ellensburg and $35^{\circ} \mathrm{F}\left(2^{\circ} \mathrm{C}\right)$ in Seattle. Thus, we should not expect absolute agreement between the reanalysis and station data, especially in the presence of sharp subgrid-scale topographic features. However, we show below that, in general, the spatial structure of ASYM primarily varies at the continental scale and, thus, the reanalysis data are well suited for assessing its spatial variability. Given the strong correspondence between the large-scale patterns of ASYM in the surface station temperature data and surface reanalyses products, we can use the reanalysis data to probe the vertical structure of ASYM.

\section{3) SOLAR RADIATION DATA}

The seasonal phasing of solar radiation at the top of atmosphere and at the surface is analyzed using satellite derived global gridded solar radiation data. We use data 

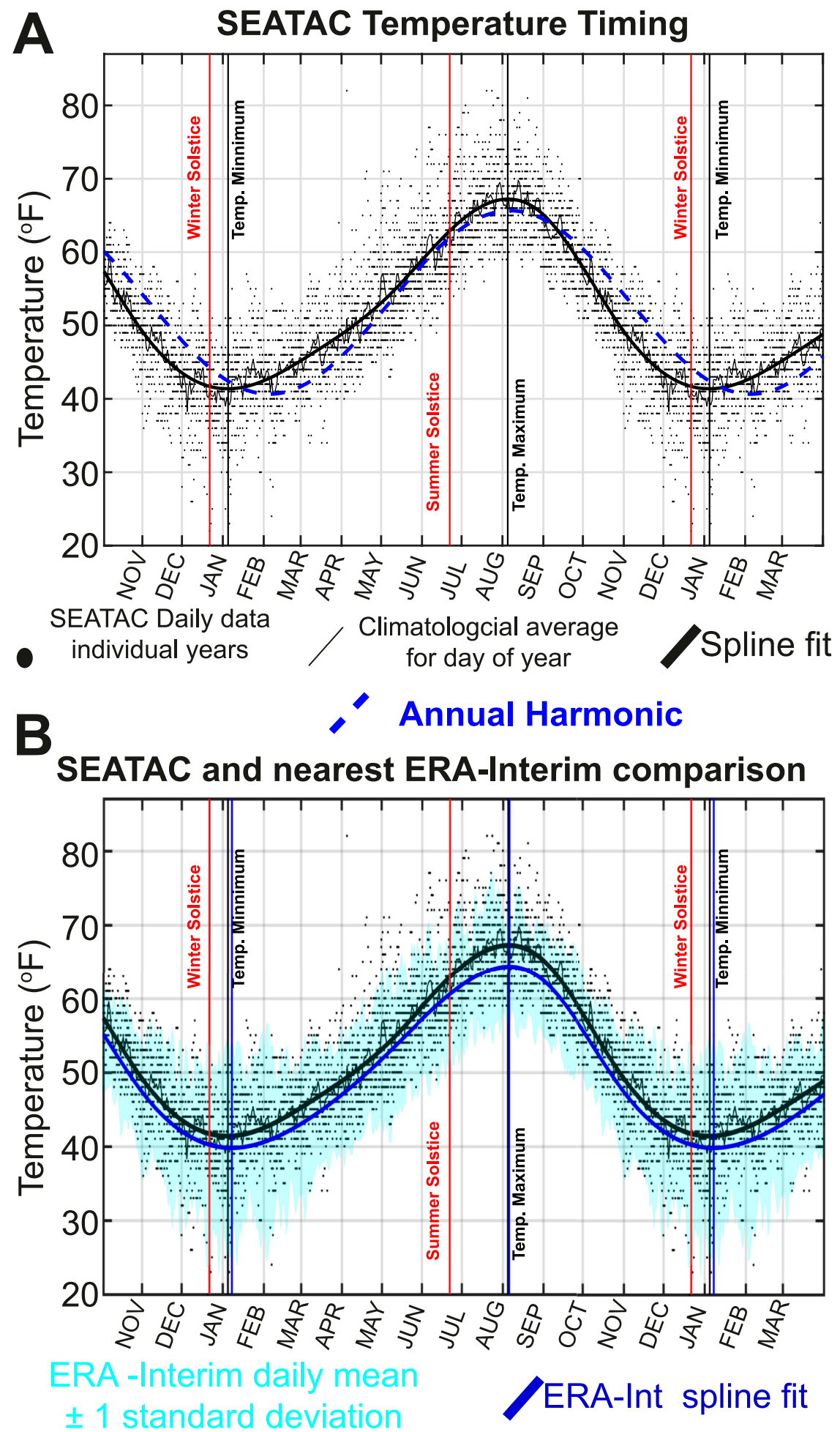

FIG. 1. (a) Seasonal cycle of daily average surface $(2 \mathrm{~m})$ air temperature $\left(T_{2 \mathrm{~m}}\right)$ at SEATAC airport on a partially repeated periodic domain. The dots show daily data for individual years. The black thin lines show the climatological average for each calendar day and the thick black line shows the spline fit to the data. The vertical black lines show the date of the spline fit maximum $\left(\tau_{\text {MAX }}\right)$ and minimum $\left(\tau_{\text {MIN }}\right)$ and the vertical red lines show the date of summer and winter solstices. The dashed blue line shows the annual harmonic fit. Ticks on the $x$ axis are on the start of each calendar month. (b) As in (a), but superimposed with $T_{2 \mathrm{~m}}$ taken 
from the Clouds and the Earth's Radiant Energy System (CERES) SYN version 4 (Kato et al. 2018; Loeb et al. 2018). The CERES data are derived from radiometer measurements on the Aqua and Terra satellites that are assimilated using a radiative transfer model, resulting in a self-consistent surface radiative flux measurements. This dataset has daily temporal resolution over the time period 2000-18 and provides global gridded coverage at $1^{\circ}$ spatial resolution.

\section{4) SEA SURFACE TEMPERATURE DATA}

While our focus is on ASYM calculated from nearsurface air temperature $T_{2 \mathrm{~m}}$, we supplement our analysis by calculating ASYM from daily SST data. SST data are from NOAA's high-resolution blended analysis, version 2 , on a $0.25^{\circ}$ global grid over the time period 1981-2016 (Reynolds et al. 2007).

\section{5) ENERGY FLUXES IN THE ATMOSPHERIC AND OCEANIC COLUMN}

The seasonal input of energy into the atmospheric and oceanic columns is calculated using the methodology described in Donohoe and Battisti (2013). These calculations use radiative fluxes at the top of atmosphere and surface from CERES 4.0 (Loeb et al. 2018; Kato et al. 2018), atmospheric energy flux convergence, and column energy tendencies calculated from ERA (Dee et al. 2011). The turbulent energy exchange between the surface and the atmosphere as a residual of the atmospheric energy budget.

\section{b. Methodology for defining the seasonal asymmetry in the lag between $T_{2 m}$ and insolation}

The methodology for calculating the seasonal asymmetry of the temperature time lag (ASYM) from both station based $T_{2 \mathrm{~m}}$ data and reanalysis data is described here. Smoothed climatological seasonal cycles of $T_{2 \mathrm{~m}}$ are created by first plotting all years of daily data on a domain of days past January first of that year (black dots in Fig. 1) padded periodically on both sides. A spline with six evenly spaced knots within the year is fit to the data (thick black line). Then the timing of the temperature maximum $\tau_{\mathrm{MAx}}$ is defined as the number of days past the summer solstice on which the smoothed $T_{2 \mathrm{~m}}$ reaches its maximum; similarly, $\tau_{\text {MIN }}$ is defined as the number of days past the winter solstice on which the smoothed $T_{2 \mathrm{~m}}$ reaches its minimum. Hence, positive values of $\tau_{\text {MAX }}$ and $\tau_{\text {MIN }}$ correspond to the $T_{2 \mathrm{~m}}$ extremes that lag the solstices, and negative values correspond to $T_{2 \mathrm{~m}}$ extremes that precede the solstices. Finally, ASYM is defined as $\tau_{\text {MAX }}$ minus $\tau_{\text {MIN }}$. Positive values of ASYM correspond to a maximum $T_{2 \mathrm{~m}}$ that lags summer solstice more than the minimum $T_{2 \mathrm{~m}}$ lags winter solstice. Hence, a positive ASYM indicates a prolonged spring and hurried autumn (i.e., in the same sense of the ASYM seen at SEATAC in Fig. 1); negative ASYM indicates a hurried spring and prolonged autumn. ASYM is calculated using the spline fit to the data because, even with 70 years of data (e.g., at the SEATAC station shown in the top of Fig. 1), the climatological average for a given calendar day (thin black line) is fairly jumpy from day to day due to random sampling of synoptic variability and this would cause the timing of the extrema to have some random component about the longer time scale seasonal evolution of temperature. We chose a spline with $6 \mathrm{kt}(1 \mathrm{kt}$ $\approx 0.51 \mathrm{~m} \mathrm{~s}^{-1}$ ) because this choice removes the highfrequency structure of the synoptic variability while retaining the temporal structure of the seasonal evolution. Alternative choices for the number of knots between 3 and $12 \mathrm{kt}$ do not significantly change the results presented here. At some locations, the smoothed seasonal cycle of $T_{2 \mathrm{~m}}$ has more than one local temporal maximum and minimum. This occurs at 8 of the 3096 stations and $<2 \%$ of the area of extratropics in the ERA data (denoted by gray crosses over the stations and gray stippling over the ERA data in Fig. 2). In these cases, $\tau_{\text {MAX }}$ and $\tau_{\text {MIN }}$ are defined by the timing of the absolute extrema in the smoothed $T_{2 \mathrm{~m}}$. In these regions, $\tau_{\mathrm{MAX}}$ and $\tau_{\text {MIN }}$ are potentially sensitive to small differences (spatially or over different time periods used to define the climatology) in the temporal structure of $T_{2 \mathrm{~m}}$ that change which local extrema are the absolute extrema used to define $\tau_{\text {MAX }}$ and $\tau_{\text {MIN }}$.

The seasonal asymmetry in downward surface solar radiation is calculated using the same methodology used to calculate the seasonal asymmetry of the temperature lag.

\section{Global structure of ASYM}

In this section, we present global maps of ASYM calculated from the comprehensive set of surface station data and from ERA. We also present the vertical

from the nearest grid point to SEATAC in the ERA-Interim product. The light blue shaded area represents plus and minus one standard deviation of the ERA data. The solid blue line is the spline fit to the ERA data and vertical blue lines show the date of the $\tau_{\mathrm{MAX}}$ and $\tau_{\mathrm{MIN}}$. The monthly ticks along the abscissa indicate the first day of the month here and elsewhere in this paper. 


\section{A Time lag of maximum temperature-- $\tau_{\mathrm{MAX}}$}

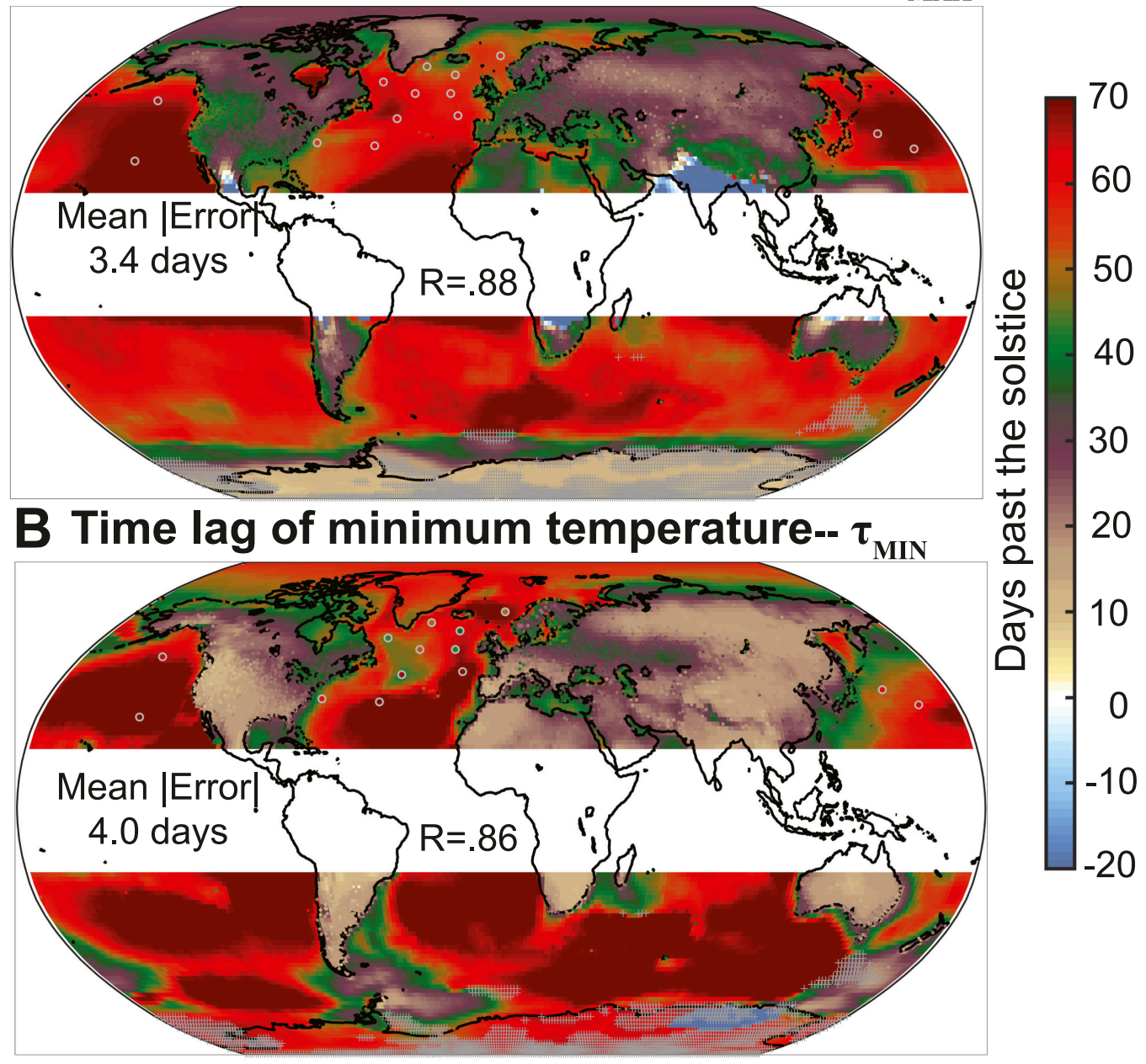

\section{Asymmetry of Seasonal Time lag (A-B)}

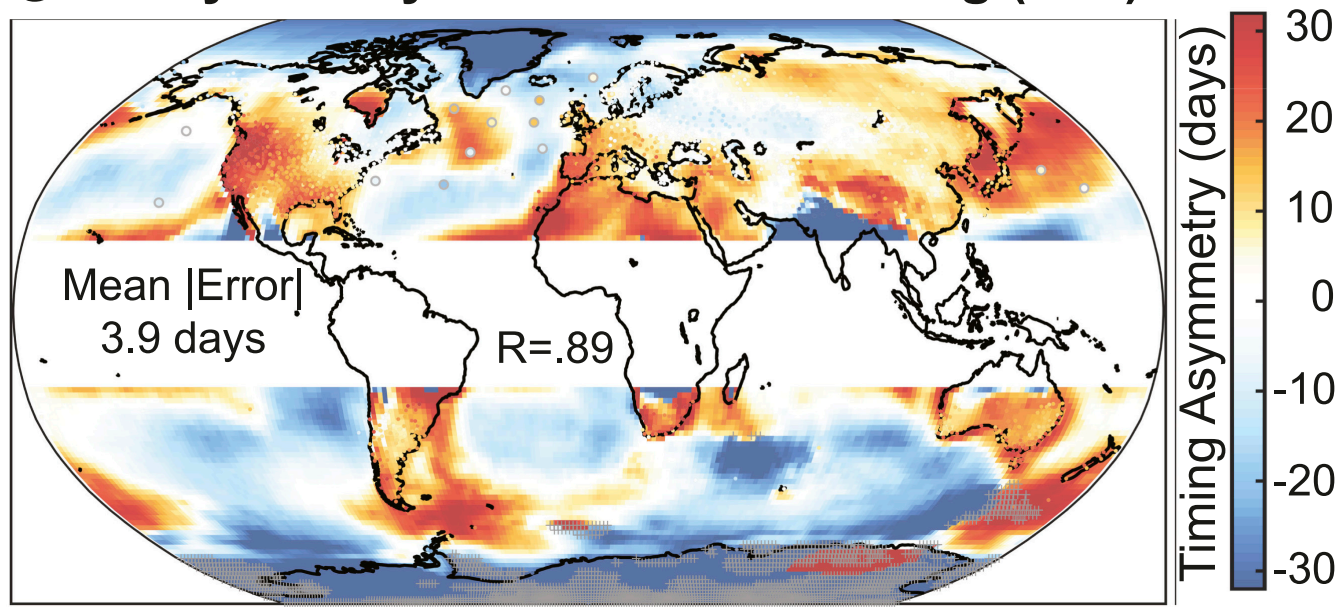

FIG. 2. (a) Time lag of maximum temperature relative to the summer solstice $\left(\tau_{\text {MAX }}\right)$. Colors show results from the gridded ERA $T_{2 \mathrm{~m}}$ data and the individual dots show the location of the station data color coded by the time lag given by the common colorbar in the upper right. The gray stippling indicates ERA grid points with more than one temporal minimum/maximum in the smoothed $T_{2 \mathrm{~m}}$ time series and the gray crosses through a station indicate the same for station data. (b) As in (a), but for the time lag of the minimum temperature relative to the winter solstice $\left(\tau_{\text {MIN }}\right)$. (c) The asymmetry (ASYM) in the timing of the seasons defined as (a) minus (b). This panel uses the color bar on the lower right. The spatial correlation $R$ between values at all stations and that at the nearest grid point is shown in the middle of each plot along with the mean absolute difference. 
structure of ASYM derived from reanalysis and highlight some curious features.

\section{a. Correspondence between $\tau_{\mathrm{MAX}}, \tau_{\mathrm{MIN}}$, and ASYM calculated from station and reanalysis data}

Maps of $\tau_{\mathrm{MAX}}, \tau_{\mathrm{MIN}}$, and ASYM calculated using the station data and calculated using the ERA data are shown in Fig. 2. Dots represent the station values and the underlying colors represent the ERA values. For each of the three quantities, values calculated from the station data are in good agreement with those calculated using the ERA data (particularly over land where it is difficult to discern the two). We quantify the correspondence between the station-based metrics and those calculated in the ERA using the mean absolute difference between the station calculation and that in the nearest-neighbor ERA grid point. The mean absolute difference is 3.4 days in $\tau_{\mathrm{MAX}}, 3.4$ days in $\tau_{\mathrm{MIN}}$, and 3.9 days in ASYM. The spatial correlation between station based and ERA-based metrics is 0.88 for $\tau_{\mathrm{MAX}}$, 0.85 for $\tau_{\text {MIN }}$, and 0.89 for ASYM. A scatterplot of ASYM calculated at each station versus that calculated from the nearest-neighbor ERA gridpoint (see Fig. A1 in the appendix) shows strong correlation with a slope near 1, and a small ERA offset in ASYM (ASYM in the station data is 0.2 days greater than that in ERA on average). Similar results (with slightly lower correlations and mean absolute differences) are found when the ERA is replaced with $T_{2 \mathrm{~m}}$ from the NCEP reanalysis product (Fig. A2). There are large differences between ASYM calculated from data from the the 14 ocean weather ship (OWS) stations and that found in the collocated ERA data: ERA-based ASYM values are predominantly negative over the ocean-with the exception of the western side of the ocean basins-whereas the OWS data feature values of ASYM near zero or positive, especially in the North Atlantic. We return to this discrepancy in section $4 b$.

Given the good correspondence between ASYM identified in the surface reanalysis data and that from the $T_{2 \mathrm{~m}}$ station observations at the regional scale, we will extend the analysis of ASYM into the troposphere using the reanalysis data to help illuminate the relevant mechanisms that affect ASYM. We note that, with the exception of several high-altitude stations, we have very few direct observational constraints on ASYM calculated above the surface and must rely on the reanalysis products for this calculation.

\section{b. Surface timing of seasonal cycle}

In general, $\tau_{\mathrm{MAX}}$ and $\tau_{\mathrm{MIN}}$ both show short lags over continental regions and long lags over marine regions (Fig. 2); these differences are expected due to the large thermal inertia of the ocean versus the small thermal inertia of land and ice (Stine et al. 2009; Hasselmann 1976).

Westerly winds advect ocean-influenced air onto the western side of the continents, resulting in larger values of $\tau_{\text {MAX }}$ and $\tau_{\text {MIN }}$ on the western side of the continents than on the eastern side. Characteristic values of $\tau_{\text {MAX }}$ and $\tau_{\text {MIN }}$ are around 50 days in the western continents and around 20 days in the interior and along the eastern edge of the continents (Fig. 2). Westerly winds advect continental-influenced air over the western ocean basins, resulting in $\tau_{\text {MAX }}$ and $\tau_{\text {MIN }}$ values that are around 40 days, shorter than those over the central and eastern ocean basin ( $\sim 80$ days; Fig. 2$)$.

In addition to the large-scale similarities in the spatial maps $\tau_{\mathrm{MAX}}$ and $\tau_{\mathrm{MIN}}$ associated with the contrasting heat capacity of land and ocean, there are substantial regional-scale differences in $\tau_{\mathrm{MIN}}$ and $\tau_{\mathrm{MAX}}$. Figure 2 features the expected gradient from large lags on the western side of continents to smaller lags in the continental interior and east side of the continents that is especially evident in $\tau_{\mathrm{MAX}}$ over North America and Eurasia and in $\tau_{\mathrm{MIN}}$ over northern Europe. In contrast, over North America $\tau_{\mathrm{MIN}}$ increases gradually eastward with values around 10 days along the West Coast of the United States and values of around 30 days on the East Coast and even larger values around the Great Lakes (Fig. 2b). Hence, the west-east gradient of $\tau_{\mathrm{MIN}}$ is opposite of that seen in $\tau_{\mathrm{MAX}}$ and opposite of what is expected based on the advection of maritime air into the continents by the climatological westerly winds. A similar feature is seen over southwestern Europe with small values of $\tau_{\text {MIN }}(\sim 10$ days $)$ just downwind of the Atlantic and $\tau_{\text {MIN }}$ increasing (to $\sim 40$ days) in eastern Europe.

There are pronounced differences between $\tau_{\text {MAX }}$ and $\tau_{\text {MIN }}$ in the high latitudes of both hemispheres: $\tau_{\text {MAX }}$ has small values over ice covered regions ( $\sim 10-20$ days), especially over the Greenland and Antarctic Ice Sheets, whereas $\tau_{\text {MIN }}$ has large values ( $\sim 60$ days). The small values of $\tau_{\text {MAX }}$ are likely due to the poor conduction of heat through ice which effectively isolates the atmosphere from the underlying surface and, additionally, to the fact that temperatures in the marginal ice zone are pegged near the freezing point in the summer. The larger values of $\tau_{\text {MIN }}$ result from gradual cooling during the polar night until the sun rises again in the spring. Over northern India, $\tau_{\text {MAX }}$ has values of less than -20 days, indicating that the maximum in $T_{2 \mathrm{~m}}$ leads the summer solstice by more than 20 days, whereas $\tau_{\text {MIN }}$ in the same region is of order +20 days as one might expect from a continental interior. We argue below that the ASYM in this region is a consequence of the onset of the monsoon, which results in thick cloud cover that halts the seasonal warming. 
The seasonal asymmetries in the lag between $T_{2 \mathrm{~m}}$ and insolation are best highlighted by the metric ASYM (Fig. 2c). In both the station data and reanalysis data, ASYM typically shows the following:

- negative values over the ocean domain, indicating that the winter minimum in $T_{2 \mathrm{~m}}$ is delayed more than the summer maximum (exceptions include the northwestern Pacific, the North Atlantic south of Greenland, the Gulf of Mexico, the west coast of Africa, and the New Zealand sector, which is discussed further in the appendix);

- positive values over land, indicating that summer maximum temperatures lag more than winter minimum temperatures (with the exception of northern Europe, which shows little difference between $\tau_{\mathrm{MAX}}$ and $\tau_{\mathrm{MIN}}$ );

- positive values on the order of 30 days over western North America that are in contrast to the near zero values in the same latitudes $\left(45^{\circ}\right.$ to $\left.55^{\circ} \mathrm{N}\right)$ over western Europe, even though both regions are downwind of the ocean and are characterized by a maritime climate;

- negative values in the Indian monsoon region due to $\tau_{\text {MAX }}$ preceding the summer solstice; and

- negative values in the high latitudes of both hemispheres due to the long delay of winter minimum temperatures relative to the delay of the summer maximum.

ASYM has a spatial pattern that is continental in scale and has magnitudes on the order of 30 days (Fig. 2c), comparable in magnitude to the seasonal asymmetry seen in Seattle, and corresponding to a 2-month difference between the length of autumn and spring. The largest positive ASYM values are found primarily on the west coast of North America (particularly in California) with ASYM values in San Diego, Long Beach, Santa Barbara, San Luis Obispo, and San Francisco all exceeding 40 days. The largest negative values of ASYM are found at stations in Antarctica and India with values less than -50 days (offscale in Fig. 2) in five Antarctica stations including the South Pole and four stations in India.

\section{c. Vertical structure of seasonal cycle timing}

Immediately downwind of the ocean, advection of air that has been influenced by interaction with the ocean surface damps the seasonal amplitude of $T_{2 \mathrm{~m}}$ and increases the phase lag. This advection occurs primarily in the middle and upper troposphere where zonal winds are strongest and, hence, the amplitude (see Fig. 8 of Donohoe and Battisti 2013) and phase of atmospheric temperature above the boundary layer are more zonally homogeneous (see Fig. 3 of Stine and Huybers 2012) than at the surface. In order for zonal advection to influence $T_{2 \mathrm{~m}}$ overland, the upper-level seasonal temperature tendencies must be communicated downward via turbulence and radiative heating. ${ }^{1}$ A central result from the previous section (i.e., positive ASYM over the western continents) requires that near-surface zonal advection and/or the subsequent vertical communication from the midtroposphere to the surface does not operate symmetrically for seasonal cooling and warming; we examine the vertical structure of ASYM to understand why.

The land-ocean contrast in $\tau_{\text {MAX }}$ that is prevalent at the surface is nearly zonally and vertically invariant above the boundary layer with near uniform values around 45 days except for lower values over the Arctic and Siberia (Fig. 3, left column, and Fig. 4, top). The sharp gradient in $\tau_{\text {MIN }}$ seen at the surface near the West Coast of the United States is present throughout the troposphere. Interestingly, the dipole between large $\tau_{\text {MIN }}$ to the west and small $\tau_{\text {MIN }}$ to the east over the western United States at $400 \mathrm{hPa}$ is shifted eastward relative to the surface dipole-so much so that along $130^{\circ} \mathrm{W}, \tau_{\text {MIN }}$ aloft is delayed from that at the surface by almost 50 days. We speculate that the upper-level gradient in $\tau_{\text {MIN }}$ spanning the eastern Pacific Ocean and western United States is caused by the stationary high pressure ridge that is set up by the jet interacting with the Rocky Mountains during December, January, and February (Held et al. 2002; Eliassen and Palm 1961). Southerly advection of warm air west of the ridge delays the seasonal minimum temperature until the ridge breaks down in February; similarly, northerly advection of cold air east of the ridge accelerates the cooling leading to a phase advance of $\tau_{\mathrm{MIN}}$ (i.e., $\tau_{\mathrm{MIN}}<0$ ).

There is also a north-south dipole in upper-level $(400 \mathrm{hPa}) \tau_{\mathrm{MIN}}$ in both the North Pacific and North Atlantic storm-track regions with $\tau_{\text {MIN }}>60$ days on the equatorward flank and $\tau_{\text {MIN }}$ of approximately 30 days on the poleward flank (Fig. 3). We speculate that this timing results from the equatorward shift of the jet, storm track, and baroclinity during the winter months (which is farthest equatorward in February; Barnes and Simpson 2017): enhanced cooling propagates equatorward with the equatorward migration of the storm track, and thus the minimum temperature is delayed near the equatorward limit of the storm track. The upper-level $\tau_{\text {MIN }}$ in the Southern Hemisphere storm track does not display the same equatorward-poleward dipole, perhaps because the seasonal movement of the storm track is damped and more semiannual in nature in the

\footnotetext{
${ }^{1}$ This argument neglects the role of barotropic mountain waves.
} 


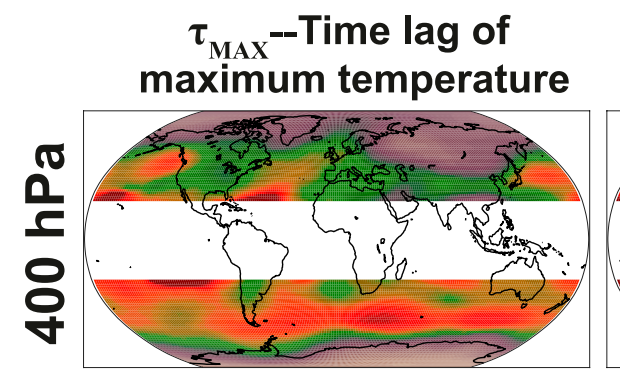

$\tau_{\text {MIN }}-$ Time lag of minimum temperature
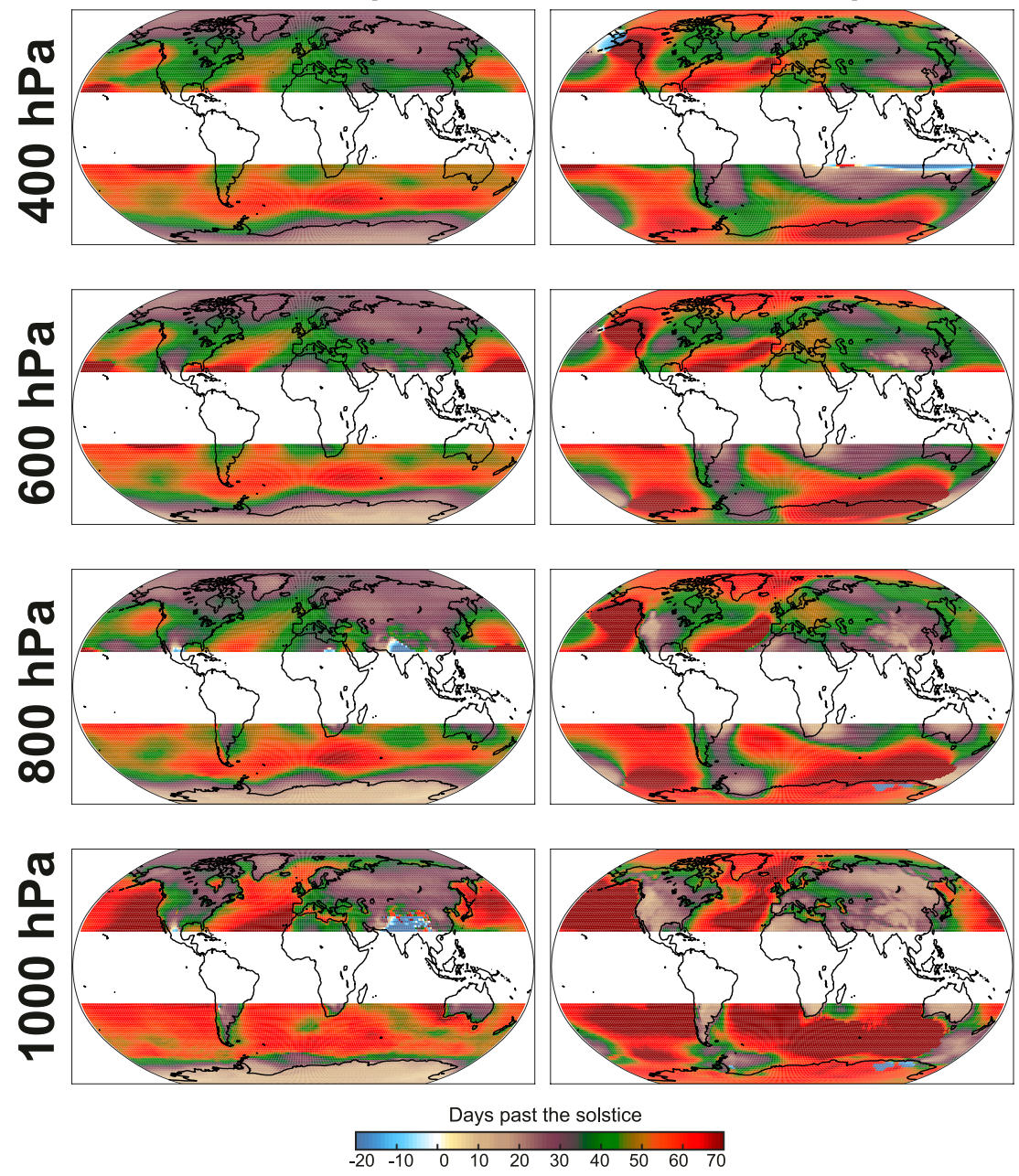
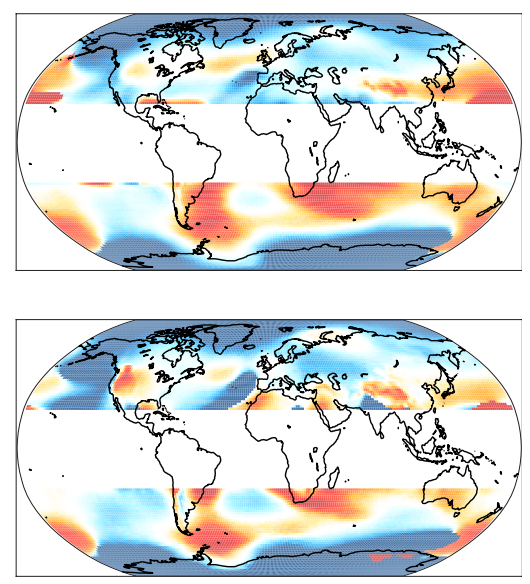

\section{ASYM--Seasonal Asymmetry of time lag}
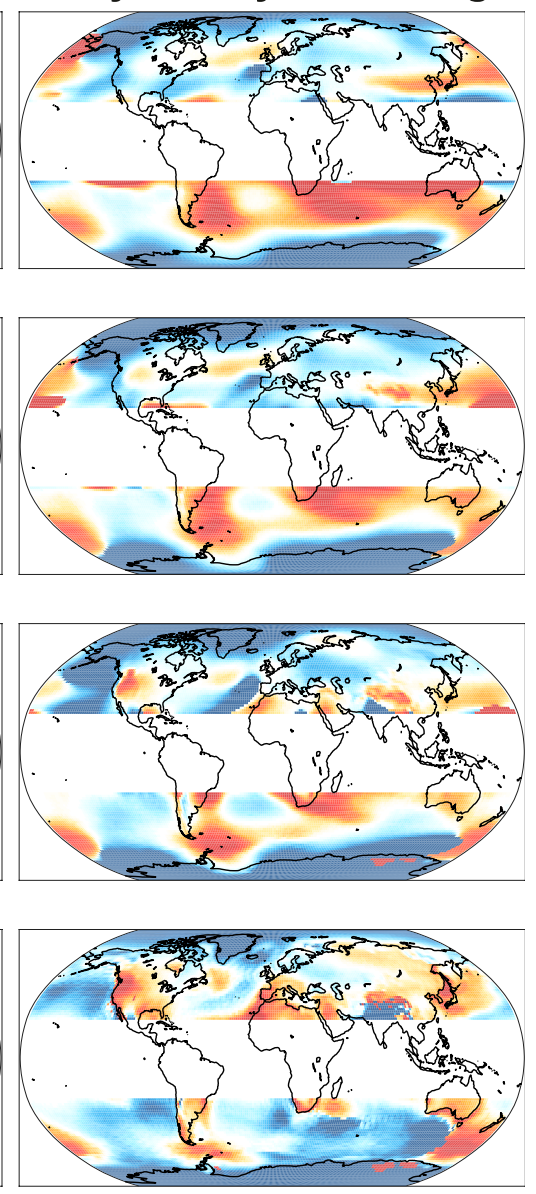

Timing Asymmetry (days)

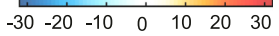

FIG. 3. Vertical structure of the seasonal timing of atmospheric temperature at various pressure levels in the ERA. Time lag of the (left) seasonal maximum temperature $\left(\tau_{\mathrm{MAX}}\right)$ and (center) minimum temperature $\left(\tau_{\mathrm{MIN}}\right)$, as well as (right) the timing asymmetry (ASYM) defined as the left column minus the right column. Each row is a different pressure level from the surface $(1000 \mathrm{hPa})$ at the bottom up to $400 \mathrm{hPa}$ at the top.

Southern Hemisphere due to the strengthening and separation of the subtropical and subpolar jets during the winter (Trenberth 1991). Because the upper-level map of $\tau_{\text {MIN }}$ has much more structure than that of $\tau_{\mathrm{MAX}}$, upper-level ASYM primarily reflects the structure in $\tau_{\mathrm{MIN}}$.

Figure 4 shows longitudinal cross sections of the $\tau_{\text {MAX }}, \tau_{\text {MIN }}$, and ASYM, averaged across the latitude band from $47^{\circ}$ to $57^{\circ} \mathrm{N}$, which was chosen to highlight the contrast in structure between the west coast of North America and Europe (Fig. 4). As previously noted, above $700 \mathrm{hPa}$ the zonal profile of $\tau_{\mathrm{MAX}}$ is much more homogeneous than at the surface. Across Eurasia, $\tau_{\text {MAX }}$ is nearly vertically invariant from the surface to the tropopause and has a value of approximately 30 days, indicative of continental air. This result suggests that convection from the solar-heated landmass influences the upper atmosphere during the summer. Except for over the eastern Pacific Ocean, $\tau_{\mathrm{MIN}}$ is more zonally homogeneous aloft than at the surface, with values of approximately 40 days. The wintertime stationary wave generated by the Rocky Mountains is responsible for large ( $\sim 70$ day) $\tau_{\mathrm{MIN}}$ that extends vertically throughout the troposphere in the eastern Pacific. Interestingly, this homogenized sector of high $\tau_{\text {MAX }}$ slants eastward with altitude and, thus, explains the reversal of ASYM with height seen over the U.S. Pacific Northwest.

Over the oceans, the vertical structure of $\tau_{\mathrm{MAX}}$ in Fig. 4a shows a strong vertical gradient at about $900 \mathrm{hPa}$ with less delayed and vertically homogeneous $\tau_{\text {MAX }}$ above $900 \mathrm{hPa}$. In contrast, the vertical structure of 

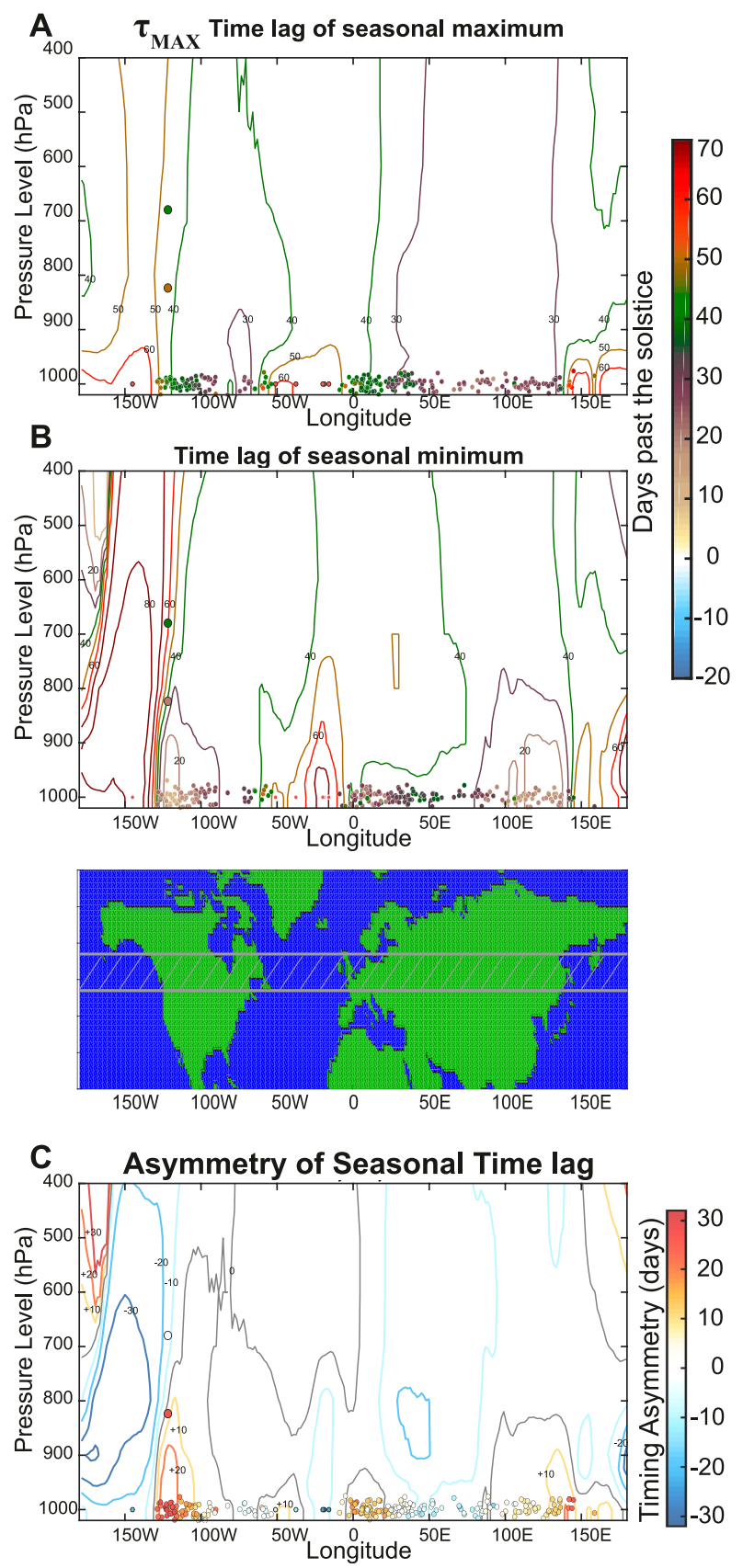

FIG. 4. Longitude-altitude cross sections of seasonal timing averaged between $47^{\circ}$ and $57^{\circ} \mathrm{N}$. (a) The time lag of the seasonal maximum relative to the summer solstice, (b) the time lag of the seasonal minimum relative to the winter solstice, and (c) the seasonal asymmetry in the timing defined as the difference between (a) and (b). The contours show the results from ERA with a contour interval of 10 days with color values according to the color bar (zero contour in gray). The color-filled circles show results from surface stations and ocean weather ships (jittered about $1000 \mathrm{hPa}$ for visual purposes) and the dots at higher levels show the highaltitude stations on Mt. Rainier, Washington. $\tau_{\text {MAX }}$ over land is vertically homogeneous from the surface all the way through the troposphere, suggesting some vertical communication between the surface and upper atmosphere during the summer. The vertical structure of $\tau_{\text {MIN }}$ shows a strong vertical gradient between 900 and $700 \mathrm{hPa}$ everywhere except over the eastern Pacific, suggesting that the surface is isolated from the upper atmosphere over most regions during the winter.

Surface station data (circles circumscribed in white in Fig. 4) and marine observations (circles circumscribed in gray) in the latitude band between $47^{\circ}$ to $57^{\circ} \mathrm{N}$ confirm the strong zonal gradients seen in $\tau_{\text {MIN }}$ and ASYM in the reanalysis data including the following features: 1) the strong gradient in $\tau_{\mathrm{MIN}}$ seen along the west coast of North America; 2) the increasing lag of $\tau_{\text {MIN }}$ moving from the West Coast of the United States toward the interior and East Coast; and 3) the large, continuous gradient in $\tau_{\text {MIN }}$ between the ocean domain and land domain over northern Europe. Also shown in Fig. 4 are $\tau_{\mathrm{MAX}}, \tau_{\mathrm{MIN}}$, and ASYM from the high-altitude stations on Mount Rainier in Washington state $\left(46.88^{\circ} \mathrm{N}, 121.7^{\circ} \mathrm{W}\right.$; plotted at the pressure level of the mean surface pressure at these stations). Data from these stations show delays in $\tau_{\mathrm{MIN}}$ that are greater than that at the surface and closer to the values seen in the reanalysis atmospheric temperature at the same pressure. Specifically, $T_{2 \mathrm{~m}}$ at Camp Muir $(680 \mathrm{hPa})$ has a prolonged cold season temperature with a delayed $\tau_{\mathrm{MIN}}(\sim 45$ days) that is halfway between that at the same pressure in the reanalysis ( $\sim 60$ days) and that at the surface ( $\sim 20$ days; Fig. A3).

\section{Mechanisms of asymmetry in the seasonal cycle of temperature}

We now explore several candidate mechanisms to explain the large-scale patterns of climatological ASYM and analyze the support for and shortcomings of each mechanism.

\section{a. Impact of clouds on the seasonal cycle of surface solar radiation}

The seasonal cycle of surface temperature is primarily driven by the amount of downwelling solar radiation reaching the surface (DSR). DSR is a function of insolation at the top of atmosphere-dictated by Earth-sun geometry-and atmospheric shortwave tranmissivity, which is governed by the concentration of atmospheric constituents that absorb (i.e., water vapor and ozone) and reflect (i.e., clouds) solar radiation. Clouds play the dominant role in determining the spatial and seasonal variability of atmospheric 
shortwave transmissivity (Taylor et al. 2007; Donohoe and Battisti 2011). Here, we explore whether seasonal variations in cloud cover can explain the spatial pattern of ASYM by way of modifying the seasonal timing of maximum and minimum DSR relative to the insolation.

We consider the seasonal cycle of DSR observed in Seattle (Fig. 5a) as an illustrative example and note at the outset that while the seasonal shape of $T_{2 \mathrm{~m}}$ in Seattle does follow (with uniform lag) the seasonal evolution of DSR, this result is limited to the region and does not apply more generally across the globe. Using the same periodic spline fit with $6 \mathrm{kt}$ that was previously applied to temperature, the date of maximum DSR is 6 July, 14 days after the summer solstice, and the minimum DSR occurs on 11 December, 10 days before the winter solstice. We define the timing of the DSR maximum and minimum relative to the solstices as $\mathrm{RAD}_{\mathrm{MAX}}$ and RAD $_{\text {MIN }}$ respectively. The offset of the DSR extrema from the solstices results from the seasonal cycle of atmospheric tranmissivity that most likely is due to seasonal cycle in clouds (e.g., cloud fraction and optical depth); this interpretation is supported by analysis of the direct versus diffuse DSR which shows direct DSR is minimized on 1 December and is maximized on 25 July (not shown) and is also consistent with the seasonality of precipitation in Seattle, which peaks in November and is a minimum in late July.

Unlike the relationship between TOA insolation and $T_{2 \mathrm{~m}}$ at SEATAC, Fig. $5 \mathrm{~b}$ shows that $T_{2 \mathrm{~m}}$ lags DSR by a consistent phase throughout the seasonal cycle; $\tau_{\text {MIN }}$ lags $\mathrm{RAD}_{\mathrm{MIN}}$ by 24 days [14 days $-(-10$ days $)=24$ days] and $\tau_{\text {MAX }}$ lags RAD MAX $_{\text {by }} 30$ days (44 days -14 days $=30$ days). Thus, the seasonal phasing of Seattle temperature is consistent with what is expected in a continental climate due to local (1D) processes forced by DSR with seasonally invariant heat capacity and local feedbacks. Under these assumptions, the temperature response lags the DSR by a constant phase across the seasonal cycle, with the phase determined by the ratio of the heat capacity to the damping (Crowley and North 1988). Indeed, the smoothed seasonal cycle of SEATAC temperature (green line in Fig. 5b) appears to lag the DSR (black line) by a fixed phase throughout the seasonal cycle. This is quantified in the inset of Fig. $5 b$ by comparing DSR (ordinate) to the temperature (abscissa) at SEATAC with the latter lagged by a (seasonally invariant) time lag of 25 days; the two time series are strongly correlated at $R^{2}=0.99$, indicated by a straight line (black dots in the inset of Fig. 5b). In contrast, the same plot of temperature versus insolationwith the optimal time lag recalculated (32 days) — produces an hourglass structure (red dots) that is indicative of a time lag between insolation and temperature that varies with season.

Seasonal variations in atmospheric shortwave transmissivity play a first-order role in the seasonality of DSR in Seattle; transmissivity varies by a factor of 2 from 0.3 to 0.6 between summer and winter, respectively, which is smaller than-but still significant when compared to-the seasonal cycle of daily mean insolation, which varies by more than a factor of 4 (between 105 and $480 \mathrm{~W} \mathrm{~m}^{-2}$ ).

These results motivate the following questions: How much does the seasonality of cloud cover alter the seasonal timing of the DSR that drives surface temperature changes across the globe? Can cloud-induced shifts in the DSR extrema relative to the solstices explain the large-scale patterns of ASYM in the $T_{2 \mathrm{~m}}$ shown in Fig. 2? To answer these questions, we quantify the seasonal asymmetry of DSR with the metric $\mathrm{RAD}_{\text {ASYM }}$, defined to be the time of the DSR maximum relative to summer solstice $\left(\mathrm{RAD}_{\mathrm{MAX}}\right)$ minus the time of the DSR minimum relative to winter solstice $\left(\right.$ RAD $\left._{\mathrm{MIN}}\right)$. RAD $_{\text {ASYM }}$ can be positive or negative, with positive (negative) values indicating a summer maximum that is more (less) delayed than the winter minimum. For example, $\operatorname{RAD}_{\mathrm{ASYM}}$ has a value of 24 days $[14$ days $-(-10$ days $)=$ 24 days] for Seattle.

In situ DSR measurements of sufficient length to

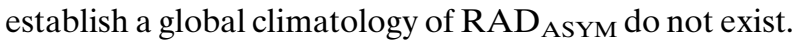
Thus, we calculate $\mathrm{RAD}_{\text {ASYM }}$ from the satellite-derived gridded climatological DSR record from CERES satellite data. The CERES data from the nearest gridpoint to Seattle (blue dots and lines in Fig. 5a) are in excellent agreement with the local radiometer data in absolute magnitude, internal variability and, most importantly, the phasing of the seasonal cycle in DSR, with RAD $\mathrm{MIN}_{\mathrm{N}}$

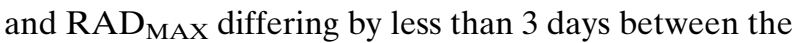
two datasets. In the appendix we show that RAD ASYM calculated from CERES is in close agreement with that calculated using in situ DSR observations at other stations in the National Solar Radiation Database of the United States (see Fig. A5; Sengupta et al. 2018), albeit with substantial disagreement on the amplitude of the seasonal cycle in DSR. Specifically, station data confirm the positive RAD $_{\text {ASYM }}$ values seen in the northern latitudes of the Unites States extending from the Pacific coast to the midwest and the negative $\mathrm{RAD}_{\mathrm{ASYM}}$ values seen in the Southwest region (due to the influence of the North America monsoon), in the Southeast (i.e., Florida), and in Alaska.

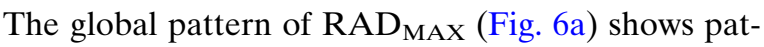
terns that are regional in extent and have values with magnitudes of approximately 30 days. $\mathrm{RAD}_{\mathrm{MAX}}$ is positive over most of the United States with largest 


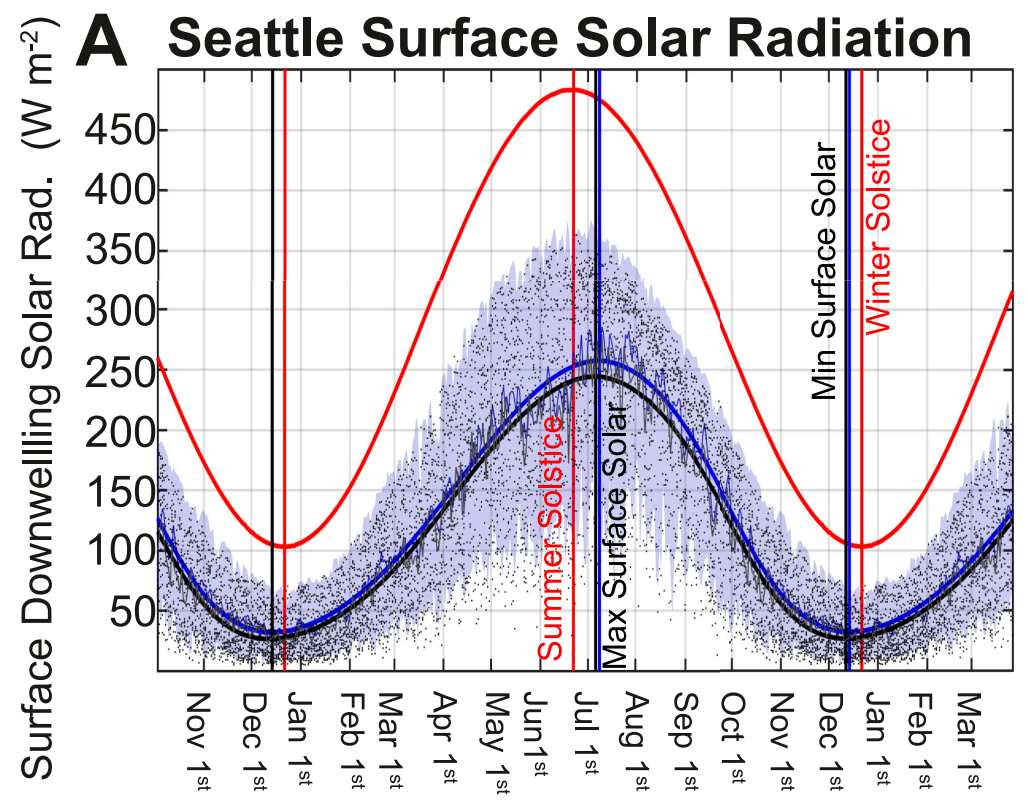

/ UW Seattle Surface Solar B / Insolation
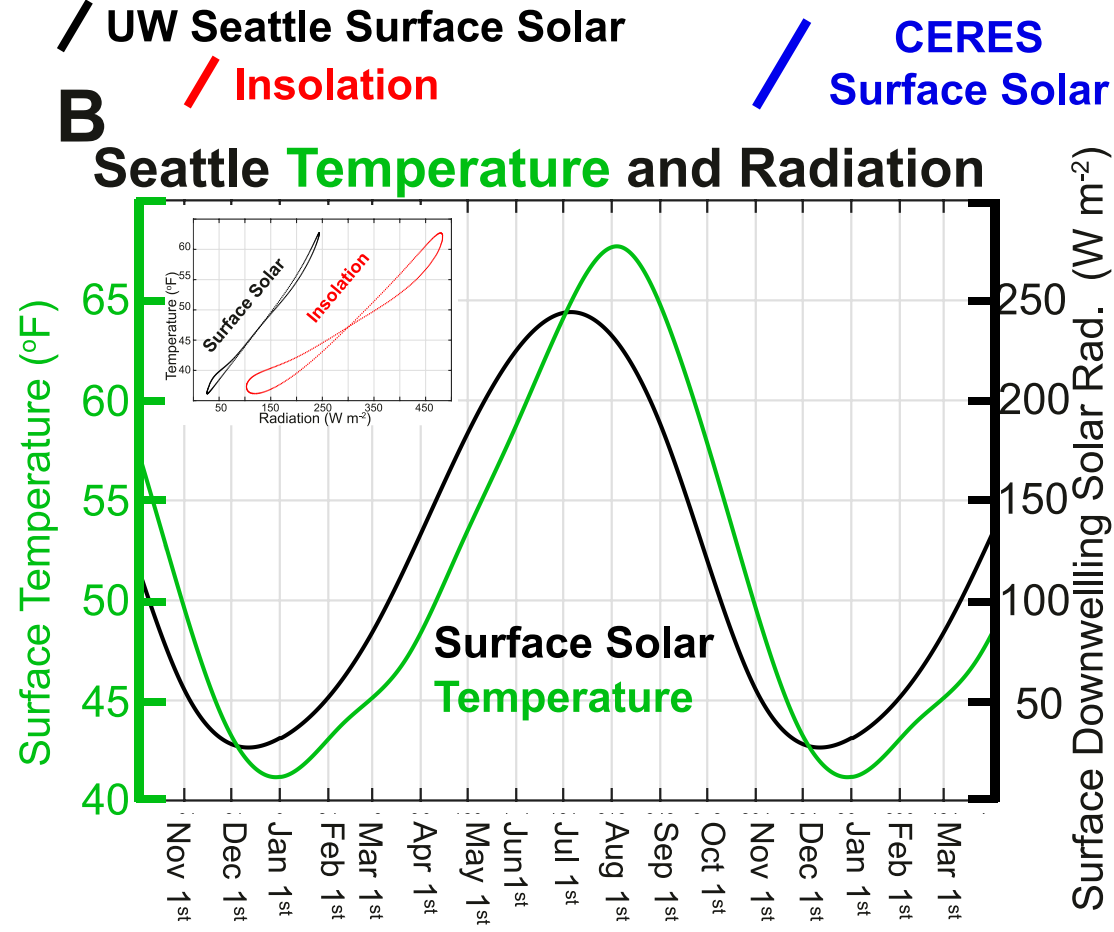

FIG. 5. (a) Seasonal time series of the downwelling surface solar radiation measured at the University of Washington (UW ATG), Seattle, (black) and at the nearest gridpoint of the CERES data (blue). Black dots show the individual daily mean values at UW ATG; the thin black line is the climatological mean for the calendar day and the thick black line is the spline fit. The shaded blue area is bounded by the maximum and minimum CERES values for the calendar day over the record (2000-18), the thin blue line is the climatological mean for the calendar day, and the thick blue line is the spline fit. The red line shows the (top-ofatmosphere downward) insolation from CERES. Vertical black and blue lines show the timing of the (spline fit) maximum and minimum surface solar radiation in the CERES and UW ATG data, respectively, and the vertical red lines show the summer and winter solstice. (b) Seasonal time series of the spline fit UW ATG surface solar radiation (black) and $T_{2 \mathrm{~m}}$ at SEATAC (green). The inset in (b) shows the relationships between $T_{2 \mathrm{~m}}$ at SEATAC and surface solar radiation at an optimal lead of 25 days (black) and between $T_{2 \mathrm{~m}}$ at SEATAC and the top-of-atmosphere insolation at an optimal lead of 32 days (red). 


\section{A Timing of maximum surface solar}

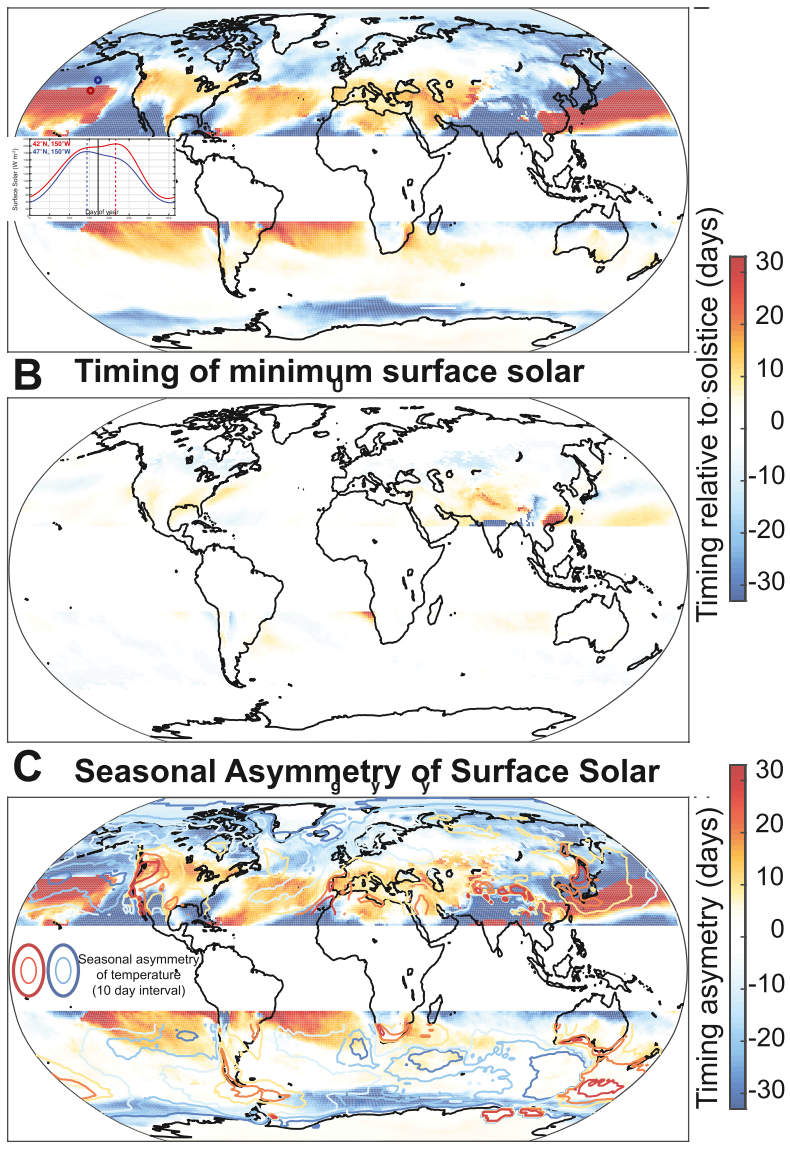

FIG. 6. (a) Timing of maximum in surface solar radiation relative to the summer solstice from the CERES dataset. (b) Timing of seasonal minimum of surface solar radiation relative to the winter solstice. (c) Seasonal asymmetry of surface solar radiation defined as the difference between (a) and (b). The contours show the seasonal asymmetry of surface temperature (ASYM) from the ERA surface data (repeated from Fig. 3) with a contour interval of 10 days using the same color bar as the surface solar timing (zero contour is omitted). In (a), the inset shows the time series of downwelling surface solar radiation at two grid points straddling the strong north-south gradient in the North Pacific (marked by circles south of Alaska on the map) with timing of the maximum shown by the vertical lines.

values on the West Coast. RAD MAX $_{\text {is }}$ positive in the Mediterranean region and near zero in northern Europe. Negative values of RAD MAX $_{\text {are seen in the }}$ monsoon regions of India, Southeast Asia, Africa, and southwestern North America where cloud cover increases well before the summer solstice and is sustained thereafter, resulting in maximum DSR prior to monsoon onset. Over the oceans, there is a pronounced northsouth dipole of $\mathrm{RAD}_{\mathrm{MAX}}$ in the North Pacific, North Atlantic, South Pacific, and South Atlantic with positive values on the equatorward flank of the storm track and negative values on the poleward flank. The sharp northsouth dipole in $\mathrm{RAD}_{\mathrm{MAX}}$ is a genuine feature of the data that we illustrate in the inset of Fig. 6a by plotting the time series of DSR at two points on different sides of the dipole in the North Pacific (indicated by the red and blue circles on the map). To the south of the nodal line, $\mathrm{RAD}_{\text {MAX }}$ occurs 30 days after the summer solstice (red time series) whereas to the north RAD $\mathrm{RAX}_{\mathrm{X}}$ occurs 30 days before the summer solstice (blue time series). This dipole reflects a poleward shift of the storm track from spring to summer, with reduced cloud cover prior to the shift (i.e., in the spring) on the poleward side and after the shift (i.e., in the late summer) on the equatorward flank.

The negative values of $\mathrm{RAD}_{\mathrm{MAX}}$ in the marginal ice zones, especially in the Southern Ocean, reflect the retreat of sea ice prior to the summer solstice by the following mechanism: the high surface albedo of the ice in the spring reflects solar radiation incident on the surface and a portion of this upwelling solar radiation from the surface is reflected back to surface by clouds (Taylor et al. 2007; Donohoe and Battisti 2011). The presence of ice in the spring enhances both upwelling solar radiation at the surface and DSR with a net decrease in solar radiation absorbed at the surface. Thus, the negative values of $\mathrm{RAD}_{\mathrm{MAX}}$ in the marginal ice zones do not accelerate the timing of $\tau_{\mathrm{MAX}}$ since the phase advanced DSR is not indicative of the timing of net solar input to the surface.

The global pattern of the timing of the DSR minimum relative to the winter solstice $\left(\mathrm{RAD}_{\mathrm{MIN}}\right.$; Fig. $\left.6 \mathrm{~b}\right)$ has much smaller amplitudes than that of RAD $\mathrm{RAX}_{\text {. We }}$ find no obvious explanation for this result. Because $\mathrm{RAD}_{\mathrm{MIN}}$ is everywhere smaller in magnitude than $\mathrm{RAD}_{\text {MAX }}, \mathrm{RAD}_{\mathrm{ASYM}}$ strongly resembles the map of RAD $_{\text {MAX }}$ (cf. Figs. 6a,b,c).

We now evaluate whether the seasonal timing of DSR and temperature are correlated at the global scale by comparing the spatial structure of RAD $_{\text {ASYM }}$ (colors in Fig. 6c) and ASYM (contours with the same color bar). On the west coast of North America, the regions of highest positive ASYM values and RAD $_{\text {ASYM }}$ are collocated over the Pacific Northwest and along the Pacific coast southwardto the Mexican border. In these regions, $T_{2 \mathrm{~m}}$ lags DSR by $\sim 15$ days throughout the seasonal cycle, consistent with a local continental response to solar forcing. Similarly, over western Europe ASYM and RAD $_{\text {ASYM }}$ are both generally positive over the Mediterranean region and are near zero to the north. This finding suggests that the seasonal cycle of cloudiness may explain the contrasting ASYM between the west coast of North America and Europe by way of modifying the phasing 

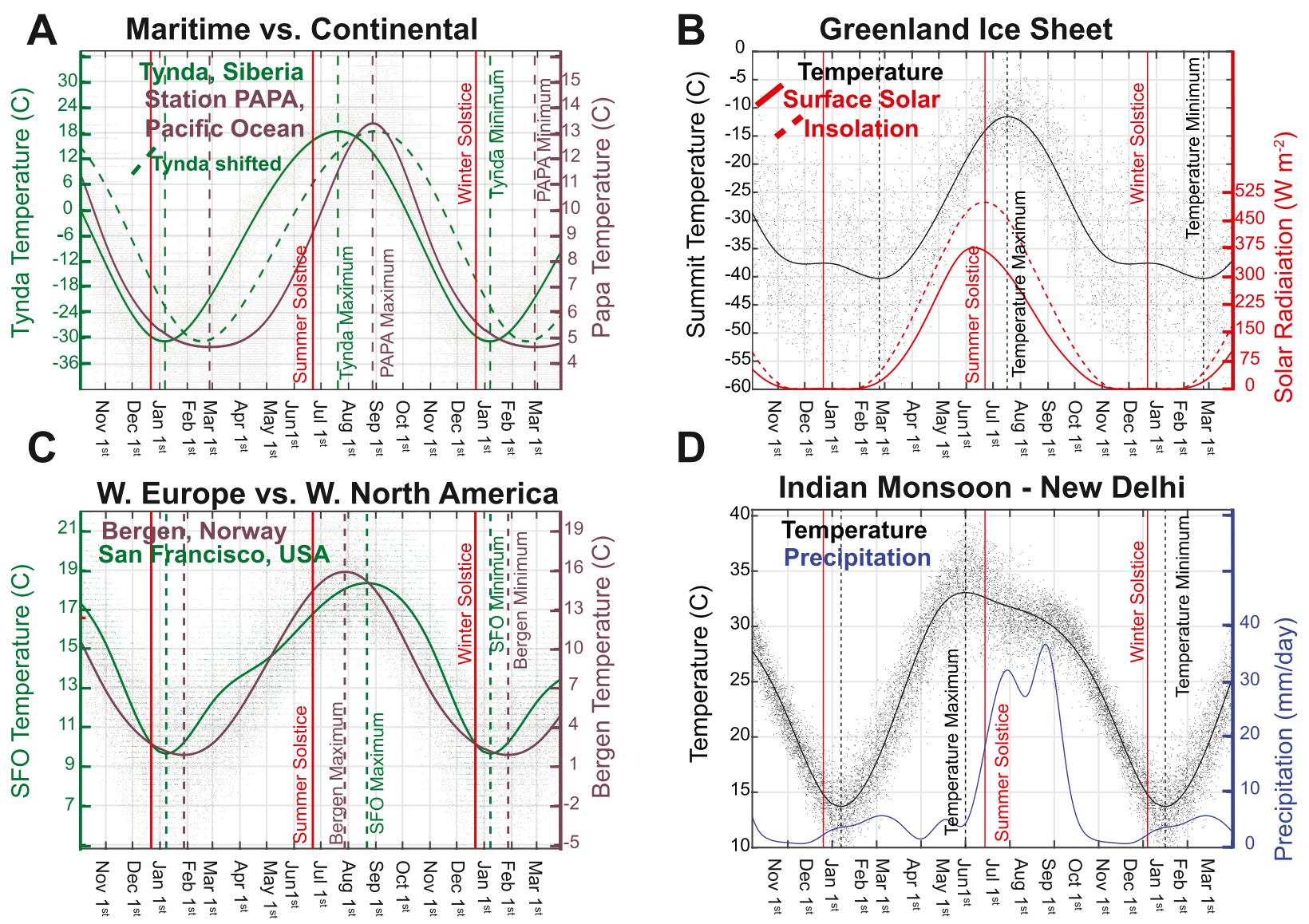

FIG. 7. (a) Comparison of the seasonal cycle of surface temperature at a typical continental location (Tynda, Siberia; green) and a maritime location (Papa; purple). The maritime record has been rescaled by a factor of 6 [cf. the left (green) and right (purple) $y$ axes] so that the seasonal cycles for visible comparison. Dots show the daily data and the lines show the spline fit to the data; vertical lines show the timing of the extrema. The dashed green line shows the continental record lagged by 42 days (such that the maxima are in phase) to highlight the different shapes of the seasonal cycle over land and ocean. (b) Seasonal times series of temperature (black) and solar radiation at the surface (dashed red) and insolation at TOA (solid red) at Greenland Summit Station. (c) As in (b), but comparing maritime climates in western North America (San Francisco airport, California; green) and western Europe (Bergen, Norway; purple). (d) Seasonal time series of temperature (black) and precipitation (blue) at New Delhi, India.

of the seasonal cycle of surface heating relative to the phasing of insolation.

On the global scale, however, ASYM and RAD $\mathrm{ASYM}$ are not significantly spatially correlated. This is especially true over the oceans where the strong north-south

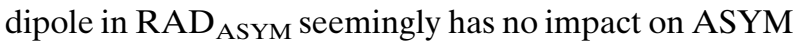
which is predominantly negative throughout the oceans except for positive values in the northwest Pacific. The spatial correlation between ASYM and RAD ASYM $_{\text {is }}$ also not significant over the global landmasses considered collectively due to the lack of correlation over the eastern half of Eurasia. These results suggest that while $\mathrm{RAD}_{\text {ASYM }}$ may offer an explanation for the contrasting ASYM in the otherwise similar maritime climates of western Europe and western North America, RAD $_{\text {ASYM }}$ is not the primary cause of ASYM at the global scale.
Thus, we look for alternative mechanistic controls of ASYM.

\section{b. Land-ocean contrast in ASYM}

\section{1) The SeAsonal eVolution of $T_{2 m}$ OVER OCEAN AND LAND}

The prevailing (first order) large-scale pattern of ASYM consists of negative values over the ocean domain and positive values over the land domain, indicative of winter minimum temperatures that are more delayed than summer maximum temperatures over the ocean and vice versa over land. We visualize the contrasting seasonal shape of $T_{2 \mathrm{~m}}$ by coplotting temperature data from a station representative of a extratropical continental climate (Tynda in the Siberia 


\section{Surface Air Temperature -- ERA 1000 hPa}

Time lag of seasonal maxmimum
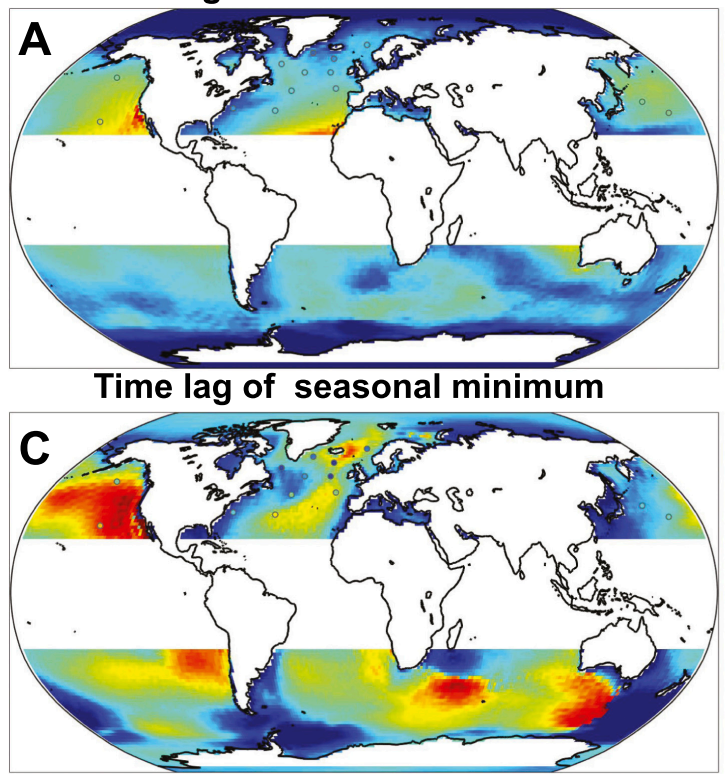

Asymmetry of Seasonal Time lag

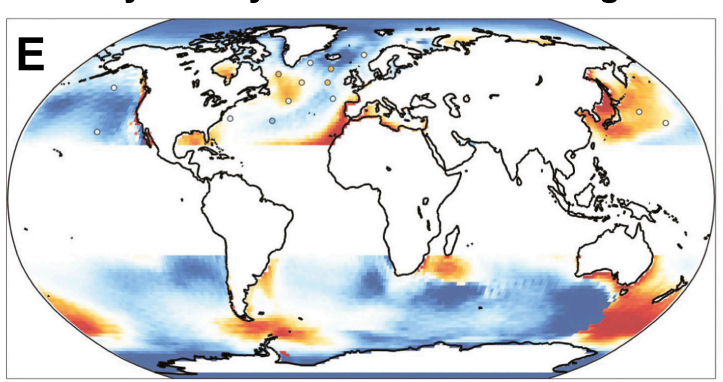

SST -- NOAA OISST

Time lag of seasonal maxmimum

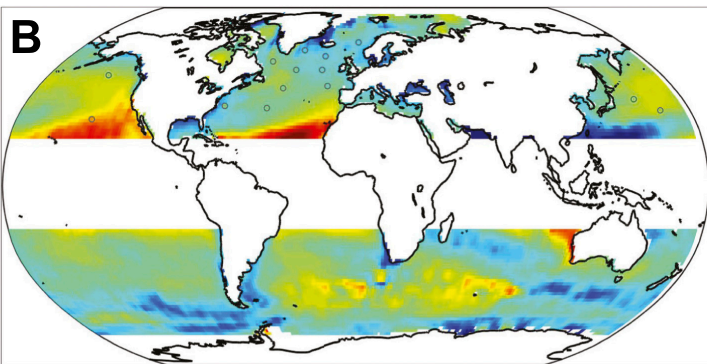

Time lag of seasonal minimum

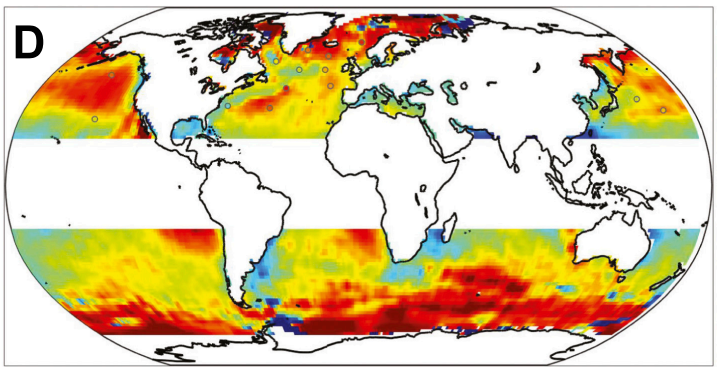

Asymmetry of Seasonal Time lag
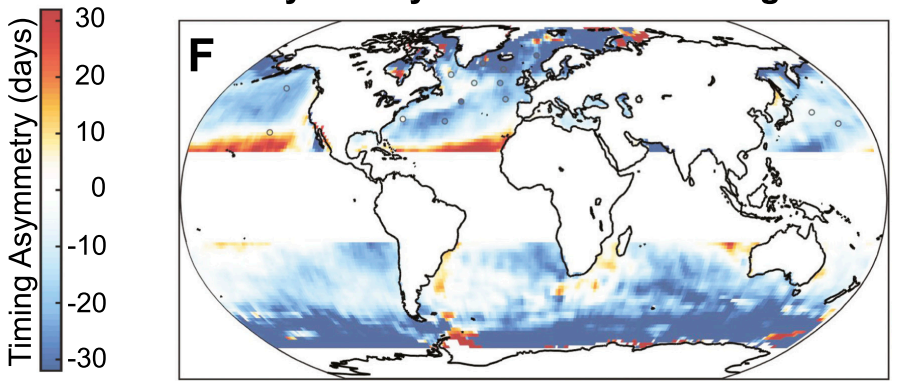

FIG. 8. Comparison of seasonal timing of $T_{2 \mathrm{~m}}$ and SST over the oceans. (a),(c),(e) $\tau_{\mathrm{MAX}}, \tau_{\mathrm{MIN}}$, and ASYM defined from surface air temperature (from ERA $1000 \mathrm{hPa}$ ). (b),(d),(f) The same quantities calculated from SST data (NOAA OISST). The dots show the ocean weather ship locations and are color coded by the timing of the station measured $T_{2 \mathrm{~m}}$ in (a), (c), and (e) and SST in (b), (d), and (f).

region of Russia; $55^{\circ} \mathrm{N}, 125^{\circ} \mathrm{E}$; elevation: $1600-\mathrm{ft}$ $(\sim 488 \mathrm{~m})$; green line, Fig. $7 \mathrm{a})$ with that of a marine climate (Ocean Weather Station Papa in the northeastern Pacific; $50^{\circ} \mathrm{N}, 145^{\circ} \mathrm{W}$; purple line). For point of reference, ASYM for the continental record is +12 days whereas that of the marine record is -20 days, which are typical continental and marine ASYM values across the globe (see Fig. 2c). The continental station is colder on average than the marine station (mean of $-4.7^{\circ}$ vs $8.3^{\circ} \mathrm{C}$ ), has a much larger-amplitude seasonal cycle (annual harmonic amplitude of $24.2^{\circ}$ vs $3.8^{\circ} \mathrm{C}$ ), and has a smaller time lag between $T_{2 \mathrm{~m}}$ and insolation (annual harmonic phase lag of 35 vs 87 days). To easily visualize differences in the shape of the seasonal cycle in these two locations, we rescale $T_{2 \mathrm{~m}}$ so that curves have the same mean vertical position and distance between temperature extremes, and shift the continental record to the right (more delay) by 52 days (equal to the phase difference of the respective annual harmonics) so that the seasonal maxima are nearly aligned (dashed red line). Comparing the dashed green and solid purple lines in Fig. 7a, we see that 1) $T_{2 \mathrm{~m}}$ in the continental record lingers in the vicinity of the summer maximum whereas the $T_{2 \mathrm{~m}}$ in the marine record is sharply peaked in summer with a delayed and more rapid temperature increase in the spring, and 2) the winter minimum in the continental record is much more sharply peaked than that in the marine record, which cools slowly during the late autumn and winter compared to the land station. The substantially different temporal evolutions seen at Tynda and the ocean station Papa are typical of those in continental and marine environments, respectively. 

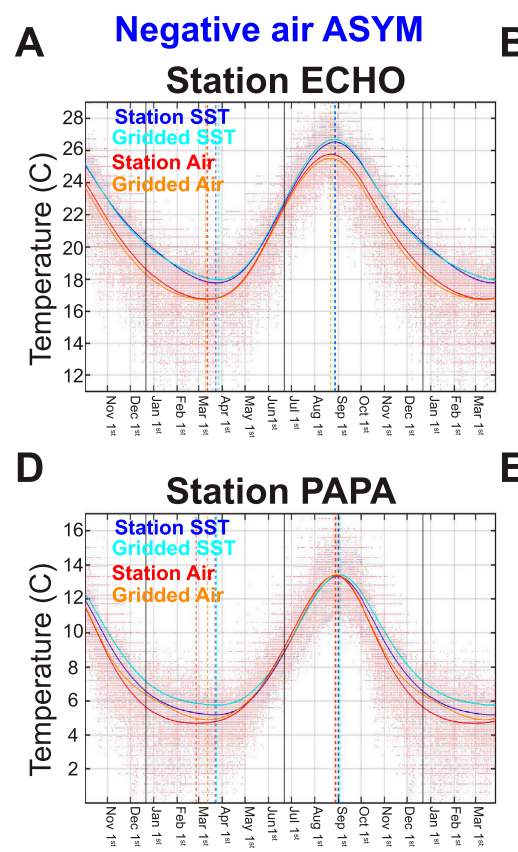

B

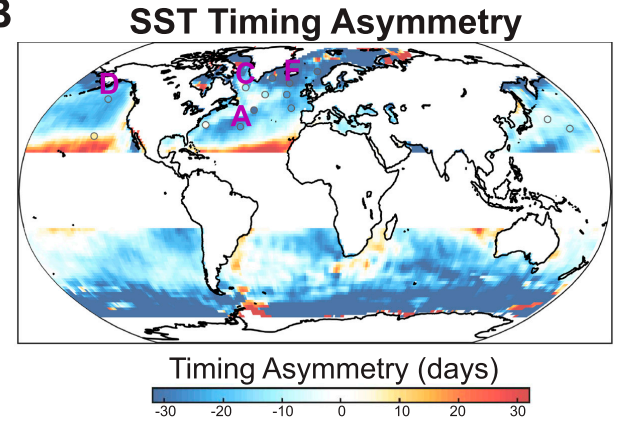

E Air temp. Timing Asymmetry

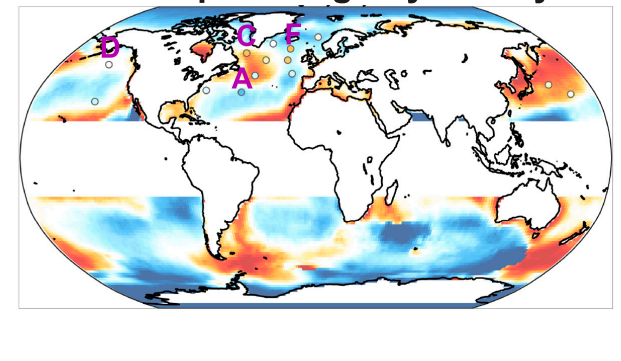

\section{Positive air ASYM}

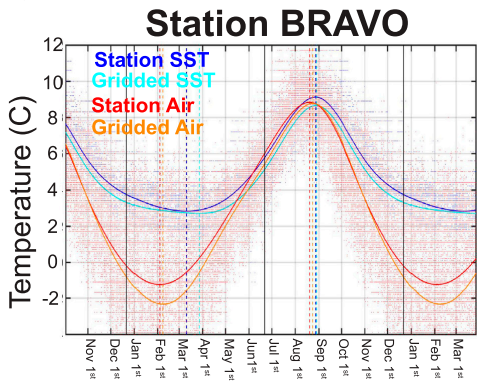

$\mathbf{F}$

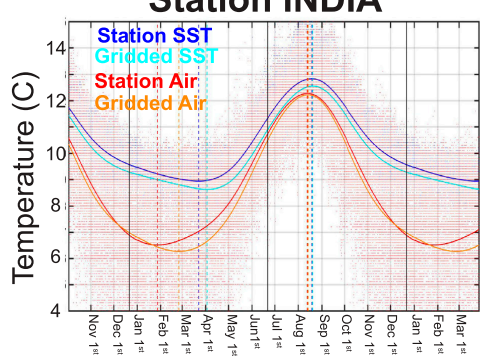

FIG. 9. (a),(c),(d),(f) Time series of smoothed seasonal cycles of SST (blue) and surface air temperature $\left(T_{2 \mathrm{~m}}\right.$; red) at selected OWS locations. The cyan line shows the NOAA OISST data and the nearest-neighbor grid point. The orange line shows the ERA $T_{2 \mathrm{~m}}$ data at the nearest-neighbor grid point. The stations are organized as follows: those with negative (positive) ASYM in $T_{2 \mathrm{~m}}$ are on the left (right) and those where the timing is well (poorly) replicated in the gridded data are on the top (bottom). (b),(e) Maps of ASYM defined from the SST data (NOAA OISST) and the ERA surface air temperature data, respectively (previously shown in Fig. 8), with the highlighted stations labeled by the letter of the panel in which they appear (just above the station location) to orient the reader.

\section{2) SEASONAL EVOLUTION OF ATMOSPHERIC AND OCEANIC BOUNDARY LAYER DEPTH}

We argue below that the ASYM contrast between land and ocean domains is due to the different seasonality in the depth of the atmosphere and ocean that is greatly influenced by the surface forcing, hereafter referred to as the boundary layer depth. The seasonality of boundary layer depth differs between the atmosphere and ocean due to the contrasting influence surface solar heating has on the stability of the two fluids: increased surface solar heating in summer (compared to winter) stabilizes the ocean boundary layer causing it to thin (shoal), whereas increased surface solar heating destabilizes the atmosphere over land and thus greatly deepens the atmospheric boundary layer (by convection) in the summer compared to winter. The seasonality of ocean mixed layer depth is amplified by the seasonal cycle in surface wind stress with reduced surface wind speed in the summer, resulting in further shoaling of the oceanic boundary layer (de Boyer Montégut et al. 2004). The lag between surface temperature and solar heating increases with increased boundary layer depth because 1 ) a deeper layer has a greater heat capacity (thermal inertia), which is more important in the ocean, and 2) a deeper layer is coupled to advective processes away from the surface, which is more important in the atmosphere. Together, this causes an earlier $\tau_{\text {MAX }}$ and delayed $\tau_{\text {MIN }}$ in SST (Figs. 8b,d), resulting in a positive ASYM in SST throughout the extratropics (Fig. 8f), and a delayed $\tau_{\text {MAX }}$ and an earlier $\tau_{\text {MIN }}$ in surface air temperature over land (Figs. 2a,b) and hence positive ASYM (Fig. 2c).

The negative ASYM in SST is due to slower cooling of the SST in the winter and early spring (blue time series in Fig. 9) in contrast to a rapid warming of SST in the fall. This temporal evolution of SST is ubiquitous in the midlatitude oceans, is well represented in the gridded reanalysis (cyan time series in Fig. 9), and differs substantially from an annual sinusoid. We illustrate the impact of seasonal variations in mixed layer depth on the seasonal evolution of SST using a simplified thermodynamic budget of the ocean mixed layer (Hasselmann 1976):

$$
\frac{d H(t) \mathrm{SST}^{\prime}}{d t}=S^{\prime}(t)-\lambda \mathrm{SST}^{\prime} .
$$

In Eq. (1), SST is the ocean mixed layer temperature, $H(t)$ is the seasonally dependent heat capacity of the oceanic mixed layer, $S(t)$ is the solar radiation entering the ocean, $\lambda$ is the sensitivity of turbulent fluxes (latent plus sensible) to surface temperature changes, and primes (') indicate anomalies from energetically 


\section{Seasonal heating of the ocean}
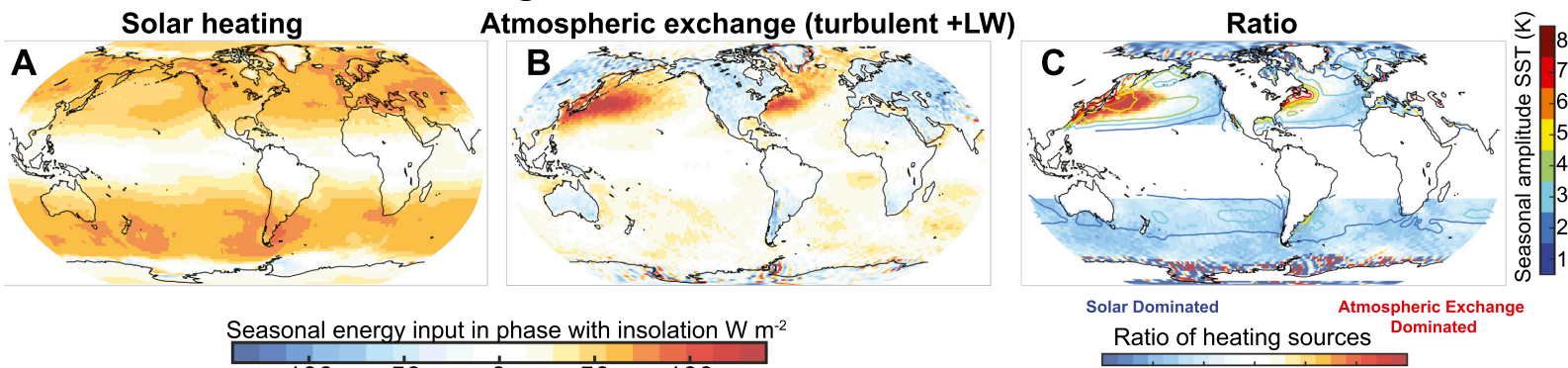

Seasonal energy input in phase with insolation $\mathrm{W} \mathrm{m}^{-2}$

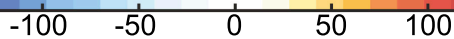

Seasonal heating of the atmosphere Solar heating

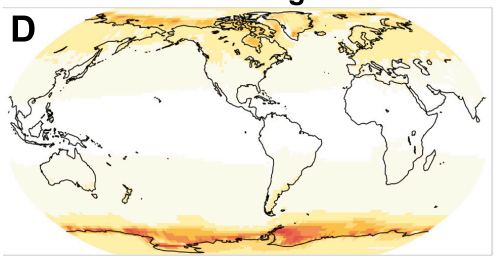
Atmospheric energy flux convergence
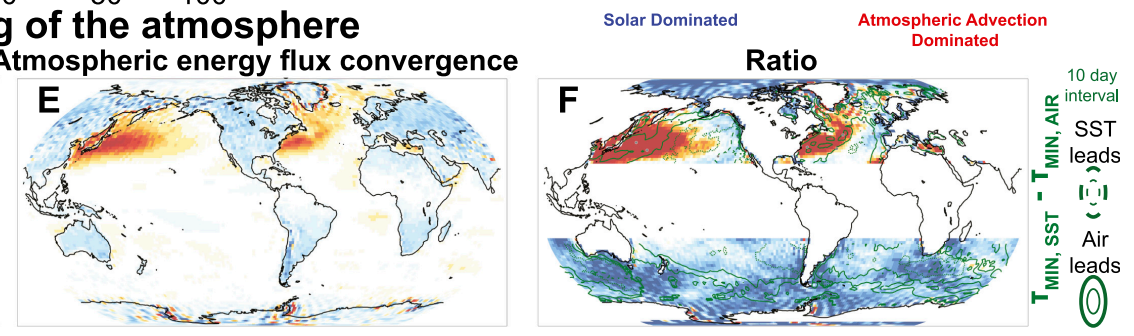

FIG. 10. The source of seasonal heating of the (a)-(c) ocean and (d)-(f) atmosphere defined as the seasonal amplitude of energy input phase with the insolation. The oceanic energy input is broken down into (a) surface solar radiation and (b) energy exchange with the atmosphere. (c) The ratio (atmospheric exchange divided by solar heating); the seasonal amplitude of SST is overlaid as contours. The atmospheric energy input is broken down into (d) solar radiation absorbed in the atmospheric column and (e) atmospheric energy flux convergence (advection). (f) The ratio (advection to solar); the phase advance of the atmospheric minimum temperature relative to the SST minimum is shown as green contours.

balanced annual mean quantities. Note that we have ignored the role of the (seasonal anomalies in) oceanic heat flux convergence and the impact of atmospheric temperature changes on the downward surface heat fluxes. A sinusoidal solar forcing results in a sinusoidal SST response for a given temporally invariant value of $H$ with amplitude (denoted by vertical brackets, II):

$$
\|\mathrm{SST}\|=\|S\| / \sqrt{(H \sigma)^{2}+\lambda^{2}},
$$

where $2 \pi / \sigma=365$ days. The phase lag $\phi$ relative to the solar forcing increases with increasing $H$ :

$$
\phi=\operatorname{atan}\left(\frac{\sigma H}{\lambda}\right) .
$$

However, $H$ is much deeper in the winter than in the summer. Hence, one would expect the decrease in SST in the winter to be less than the increase in SST in the summer and the lag between the minimum insolation and minimum SST $\left(\tau_{\text {MIN }}\right)$ would be greater than the lag between the maximum insolation and maximum SST $\left(\tau_{\mathrm{MIN}}\right)$. This characteristic slowly evolving (i.e., delayed) minimum SST is seen at all OWS stations (Fig. 9; blue lines). Numerical solutions with seasonally varying $H$ demonstrate that this expected seasonal dependence of phasing [Eq. (3)] and amplitude [Eq. (2)] of SST roughly holds for reasonable choices of temporally variant $H$ and $\lambda$ and, furthermore, that the slowly evolving SST minimum seen in Fig. 9 is replicated in these numerical simulations of Eq. (1) (not shown).

We now turn to the seasonal cycle of the surface air temperature $T_{2 \mathrm{~m}}$ overlying the ocean. In the interior of the ocean basins, the seasonal evolution of $T_{2 \mathrm{~m}}$ mirrors that of SST with $\tau_{\text {MAX }}$ nearly in phase in the two fluids and $\tau_{\text {MIN }}$ within 2 weeks of one another (cf. the red and blue time series at OWS stations Echo and Papa in Figs. 9a,d). An in-phase relationship between SST and $T_{2 \mathrm{~m}}$ is expected for an isolated (no advection, far downwind of land) atmospheric column coupled to an ocean. In such as system, the atmosphere is primarily heated seasonally by the absorption of solar radiation in the atmospheric column and damped by turbulent exchange with the ocean-with seasonal energy storage in the atmospheric column being nontrivial but smaller in magnitude (Fig. 7 of Donohoe and Battisti 2013). In such a system, the time scale of adjustment between the atmosphere and the ocean is given by the atmospheric heat capacity $\left(C p P_{S} / g\right)$ divided by the sensitivity of turbulent fluxes to the contrast between SST and $T_{2 \mathrm{~m}}$ $\left(\lambda_{\mathrm{SST}} \approx 30 \mathrm{~W} \mathrm{~m}^{-2} \mathrm{~K}^{-1}\right)$, which is approximately 4 days. Thus, the atmosphere and ocean adjust in concert to seasonal insolation changes and are driven from the top down. 
We now turn to the impact of seasonal variations in the atmospheric boundary layer depth on the seasonal evolution of $T_{2 \mathrm{~m}}$ over landmasses (the green line in Fig. 7a). During the summer, solar heating of the surface destabilizes the surface atmosphere, resulting in convection and an efficient connection between the surface and midtroposphere, where zonal advection of marineinfluenced air ameliorates the amplitude and alters the phase of $T_{2 \mathrm{~m}}$ (Stine and Huybers 2012). In contrast, during the winter, the reduced surface solar heating results in net longwave cooling of the surface that stabilizes the atmospheric boundary layer and effectively isolates the air in the boundary layer from the influence of the air aloft. The result is a rapid cooling of the surface, nearly in phase with winter solstice due to the low heat capacity of the surface and lower atmosphere. The thermodynamic decoupling between the atmospheric boundary and midtroposphere over the continents during the winter can be seen in the cross sections in Fig. 4: $\tau_{\text {MIN }}$ in the surface boundary layer is distinct from that in the free troposphere. In contrast, $\tau_{\mathrm{MAX}}$ is nearly vertically homogeneous throughout the atmosphere over the continents, suggesting strong coupling between the boundary layer and midtroposphere during the summer.

\section{3) SeAsonal CyCle of $T_{2 m}$ AND SST IN THE WESTERN OCEAN BASINS}

In contrast to the in-phase relationship between $T_{2 \mathrm{~m}}$ and SST seen in the interior of the ocean basin, immediately downwind of the continents, the winter minimum in $T_{2 \mathrm{~m}}$ is almost $4 \mathrm{~K}$ colder than and precedes the minimum in SST by over a month (e.g., at Station Bravo and India; Figs. 9c,f). We demonstrate here that the seasonal evolutions of both SST and $T_{2 \mathrm{~m}}$ in this region are profoundly impacted by atmospheric advection off the continent and, thus, depart from the expected behavior of a coupled atmospheric-oceanic column responding to seasonal changes in insolation that was developed in the previous subsection.

Equation (1) assumes that the seasonal cycle of SST is driven by solar radiation at the surface, damped by turbulent energy fluxes (via $\lambda_{\mathrm{SST}}$ ), and ignores changes in the turbulent and downwelling longwave radiation that are driven, in part, by changes in the near-surface atmospheric temperature. This assumption fails on the western side of the North Atlantic and North Pacific basins where the seasonal input of energy into the ocean surface-defined as the amplitude of the seasonal anomaly that is in phase with the insolation (see Donohoe and Battisti 2013) - is primarily associated with the atmosphere fluxing energy into (out of) the ocean column during the warm (cold) season (cf.
Figs. 10a and 10b). This strong seasonal heating and cooling of the ocean immediately downwind of the continents results from atmospheric advection off the continent that amplifies the seasonal variations in ocean energy content: 1) cold-air advection during winter pulls energy out of the ocean (via turbulent energy fluxes), further cooling the SST, and 2) warmair advection during summer pushes (anomalous) energy into the ocean, further warming the SST. In contrast, on the eastern side of the North Atlantic and Pacific and throughout the Southern Ocean, the seasonal input of energy into the ocean column is dominated by solar heating of the surface. The contrasting source of seasonal oceanic heating can be seen from a plot of the ratio of the seasonal contribution of atmosphere-ocean exchange to that of solar heating (Fig. 10c), which is $>1$ on the western half of the basins and $<1$ on the eastern half. This ratio is an excellent predictor of the seasonal amplitude of SST (shown in contours in Fig. 10c), which suggests that the amplitude of seasonal variations in SST is set by seasonal variations in atmospheric advection and is largely independent of seasonal variations in oceanic circulation. Because the seasonal atmospheric advection off the continent is nearly in phase with insolation, the phasing of the seasonal cycle of SST is well captured by Eq. (3) with the departures from a sinusoid (and the differing values of $\tau_{\text {MAX }}$ and $\tau_{\text {MIN }}$ ) due to the seasonal evolution of $H$.

The dominant atmospheric energy balance on seasonal time scales over the western ocean basins is between atmospheric advection and surface heat fluxes (cf. Figs. 10d,e). In physical terms, during the winter, westerly winds bring cold air from the continent that strongly cools (magnitude $>150 \mathrm{~W} \mathrm{~m}^{-2}$; Fig. 10e) the atmosphere over the western ocean basins. $T_{2 \mathrm{~m}}$ is $4 \mathrm{~K}$ colder than the SST with the contrast between SST and $T_{2 \mathrm{~m}}$ peaking in February (Figs. 9c,f). The cold air pulls energy out of out of the warmer ocean via upward turbulent energy fluxes $\left(\approx 150 \mathrm{~W} \mathrm{~m}^{-2}\right.$; not shown), consistent with estimates of $\lambda_{\mathrm{SST}}$. For regions in which the seasonal heating by atmospheric advection exceeds that of heating by atmospheric solar absorption (denoted by ratios $>1$ in Fig. 10f), atmospheric heat flux divergence is balanced by upward turbulent energy fluxes. Because the seasonal evolution of SST is more gradual (smaller in magnitude) than that of $T_{2 \mathrm{~m}}$, the turbulent exchange is proportional to and in phase with $T_{2 \mathrm{~m}}$. Thus, the minimum in $T_{2 \mathrm{~m}}$ occurs during the maximum in cold-air advection (atmospheric heat flux divergence), which occurs in January and February when the lateral gradient of $T_{2 \mathrm{~m}}$ between the ocean and land and the zonal wind strength are greatest. In contrast, the SST will continue to cool 
until the radiative heating exceeds the atmospheric energy flux divergence, which occurs approximately a month later.

From a Lagrangian perspective, the seasonal disequilibrium between $T_{2 \mathrm{~m}}$ and SST results from air being advected to a region of substantially different SST on the time scale of atmospheric adjustment to the SST via the turbulent energy fluxes (4 days) due to the strong lateral gradient of SST over the western ocean basin. The lateral SST gradient in the winter is a consequence of the zonal flux of cold air off the continent (Fig. 10c); thus, the $\tau_{\mathrm{MIN}}$ contrast between $T_{2 \mathrm{~m}}$ and SST results from atmospheric advection.

In the eastern ocean basins there is substantial disagreement between $\tau_{\text {MIN }}$ calculated from OWS $T_{2 \mathrm{~m}}$ and that calculated from ERA $T_{2 \mathrm{~m}}$ at the nearest neighbor (cf. the dots and colors in Fig. 9E). This discrepancy is associated with the seasonal minimum in $T_{2 \mathrm{~m}}$ in the reanalysis being more in phase with the SST minimum as compared to OWS $T_{2 \mathrm{~m}}$, which is coldest a full 2 months before the SST minimum. This bias is most prominent at OWS India (Fig. 9F) and is unrelated to biases in the SST assimilated into the ERA . One possible cause is that wintertime cold-air advection off the continents in the ERA model does not extend far enough east across the ocean basin.

\section{c. Seasonal timing in the high latitudes}

ASYM is negative in the high latitudes of both hemispheres (Fig. 2c) with values of $<-30$ days over the Arctic sea ice and the Greenland and Antarctic Ice Sheets. This seasonal asymmetry of surface temperature results from the relatively short lag between the summer solstice and time of maximum temperature $\left(\tau_{\operatorname{MAX}}=20-30\right.$ days $)$ typical of a continental climate with small surface heat capacity, and long $\tau_{\text {MIN }}$ values ( $>60$ days). These regions are effectively isolated from marine influence at all times of year. The relatively long delay in seasonal minimum temperature results from the temporal evolution of insolation, which deviates greatly from the annual harmonic above the Arctic and Antarctic Circles, where insolation flat lines at zero during the polar night (red line in Fig. 7b). The definition of the winter solstice is fairly meaningless in these regions since the minimum insolation is realized over the course of several months. We use the temperature record at Greenland Summit Station (Shuman et al. $2001 ; 72.5^{\circ} \mathrm{N}, 38.5^{\circ} \mathrm{W}$ ) over the time period 2008-18 to demonstrate the characteristic shape of the seasonal cycle of $T_{2 \mathrm{~m}}$ over the high-latitude ice sheets (black line in Fig. 7b). After a well-defined peak in temperature in mid-July, temperatures decrease steadily until the beginning of the polar night in
November. During the polar night, temperature continues to decrease slowly until just after the sun rises again in March; $\tau_{\mathrm{MIN}}$ occurs just after the end of the polar night-timing that is analogous to the timing of the minimum temperature in the diurnal cycle, which generally occurs just after sunrise because the surface continues to cool until the absorbed solar radiation exceeds the emitted longwave radiation (Holmes et al. 2013).

\section{d. Impact of monsoons on the seasonal cycle of temperature}

The onset of the Indian monsoon (around the beginning of June) heralds increased evaporative cooling of the northern Indian Ocean and an increase in cloud cover and precipitation over the continent, thereby reducing DSR and increasing the soil moisture available for evaporation and cooling the surface (Gadgil 2003). The Indian monsoon region and a small section of the North American monsoon are the only regions on Earth where $\tau_{\text {MAX }}$ occurs before the summer solstice. The timing of the temperature maximum relative to the onset of monsoonal precipitation is analyzed from the station data in New Delhi, India, which is representative of the climate in the region (Fig. 7d). Temperature rapidly increases from the seasonal minimum in December until 1 June, when the precipitation begins to ramp up (blue line). Thereafter, the temperatures gradually decline.

The beginning of this cooling period corresponds to the onset of the monsoon in the region (India Meteorological Department 2019; Webster et al. 1998) which, in the climatological average, occurs in the middle of May in southwest India and approximately a month later in northern India (see Fig. 3 of Krishnamurthy and Shukla 2000). The onset of the monsoon is coincident with an increase in atmospheric water vapor (see Fig. 3 in Singh et al. 2004), a migration of the clouds over the region (Sikka and Gadgil 1980) causing a reduction in downwelling solar radiation at the surface (Yasunari 1979) of order $60 \mathrm{~W} \mathrm{~m}^{-2}$ (see Fig. A6), and an increase in soil moisture (Nayak et al. 2018). The reduction in surface solar radiation and enhanced soil moisture act in concert to cool the surface via reduced energy input to the surface and enhanced surface energy loss via an increased upward latent heat flux. This cooling tendency prior to the summer solstice results in negative values of $\tau_{\text {MAX. }}$.

In contrast to the negative $\tau_{\text {MAX }}$ values in the Indian monsoon region, $\tau_{\text {MAX }}$ values in the East Asian monsoon region are of order +30 days. The East Asian monsoon (north of $25^{\circ} \mathrm{N}$ ) is characterized by the mei-yu front and by persistent rain and clouds within and to the 
TABLE 1. Summary of emblematic regions, their typical values of $\tau_{\max }$ and $\tau_{\min }$, the primary mechanisms responsible for $\tau_{\max }$ and $\tau_{\min }$, and the section of the paper that discusses the emblematic region.

\begin{tabular}{|c|c|c|c|}
\hline Domain & Delay & Mechanisms & Section \\
\hline \multicolumn{4}{|c|}{$T_{2 \mathrm{~m}}$} \\
\hline Mid-continent & $\tau_{\max } \sim 30$ days, $\tau_{\min } \sim 20$ days & $\begin{array}{l}\text { Low heat capacity of land; seasonal cycle } \\
\text { in atmospheric boundary layer depth }\end{array}$ & $4 b(1), 4 b(2)$ \\
\hline Midlatitude ocean, far from land & $\tau_{\max } \sim 60$ days, $\tau_{\min } \sim 80$ days & $\begin{array}{l}\text { High heat capacity; seasonal cycle in } \\
\text { ocean boundary layer depth }\end{array}$ & $4 b(1), 4 b(2)$ \\
\hline $\begin{array}{l}\text { Midlatitude ocean, immediately } \\
\text { downwind of land }\end{array}$ & $\tau_{\max } \sim 50$ days, $\tau_{\min } \sim 40$ days & $\begin{array}{l}T_{2 \mathrm{~m}} \text { and SST out of phase due to } \\
\text { atmospheric advection }\end{array}$ & $4 b(3)$ \\
\hline Polar regions; sea ice & $\tau_{\max } \sim 30$ days, $\tau_{\min } \sim 60$ days & $\begin{array}{l}6 \text { months of darkness, low heat capacity } \\
\text { in summer }\end{array}$ & $4 c$ \\
\hline India & $\tau_{\max } \sim-20$ days, $\tau_{\min } \sim 20$ days & $\begin{array}{l}\text { Reduced mid- and late-summer DSR } \\
\text { associated with monsoon onset }\end{array}$ & $4 d$ \\
\hline Seattle & $\tau_{\max }=44$ days, $\tau_{\min }=14$ days & $\begin{array}{l}\text { Seasonal cycle of DSR due to seasonality } \\
\text { of clouds }\end{array}$ & $4 a$ \\
\hline \multicolumn{4}{|c|}{ SST } \\
\hline Midlatitude ocean, far from land & $\tau_{\max } \sim 60$ days, $\tau_{\min } \sim 90$ days & $\begin{array}{l}\text { Large heat capacity; seasonal cycle in } \\
\text { boundary layer thickness }\end{array}$ & $4 b(1), 4 b(2)$ \\
\hline $\begin{array}{l}\text { Midlatitude ocean, immediately } \\
\text { downwind of land }\end{array}$ & $\tau_{\max } \sim 60$ days, $\tau_{\min } \sim 70$ days & $\begin{array}{l}\text { Atmospheric advection; high heat } \\
\text { capacity; seasonal cycle in boundary } \\
\text { layer thickness }\end{array}$ & $4 b(3)$ \\
\hline
\end{tabular}

south of the front; these rains last from early spring to early summer. In mid-July, when insolation is nearly at peak, the mei-yu front breaks up and clouds and rain become more episodic; as a result, the temperature rises and reaches a maximum 30 days after the solstices, in late July. We note that we do not consider the seasonal timing of temperature in the Southeast Asian monsoon in this study because this region is primarily equatorward of $25^{\circ} \mathrm{N}$ and, thus, has a significant semiannual component of insolation, $T_{2 \mathrm{~m}}$ and precipitation (Misra and DiNapoli 2014), which makes the definition of $\tau_{\operatorname{MAX}}$ problematic.

\section{Summary and conclusions}

The phase and amplitude of the annual harmonic in surface temperature have been used extensively in the existing literature to probe the underlying climate physics responsible for seasonality and its changes under global warming (Santer et al. 2018; Laepple and Lohmann 2009; Dwyer et al. 2012; Stine et al. 2009; Stine and Huybers 2012; Donohoe and Battisti 2013). We have demonstrated that the departures of $T_{2 \mathrm{~m}}$ from the annual harmonic are substantial, vary greatly at the regional scale across the globe, and are well encapsulated by the metric ASYM, which is the seasonal asymmetry in the lag between the solstices and the temperature extrema. Table 1 provides a summary of ASYM values identified in different regions, the proposed relevant physical mechanism, and the section of the manuscript where we discuss the mechanism.
To emphasize how different the temporal evolution of the seasonal cycle can be between different regions of Earth, we draw the reader's attention to the panels of Fig. 7, which shows disparate but emblematic examples of contrasting seasonal cycles (scaled and shifted for ease of comparison). Figure 7a shows a typical maritime seasonal cycle of $T_{2 \mathrm{~m}}$ (station Papa, with a prolonged seasonal minimum; purple line) and a continental seasonal cycle of $T_{2 \mathrm{~m}}$ (Tynda, Siberia, with a prolonged seasonal maximum; green line). Figure $7 \mathrm{c}$ shows two maritime climates on the west coast of the continents, one with a long duration warming period in North America (San Francisco, California; green line) and one with a short duration warming period in Europe (Bergen, Norway; purple line). The contrasting shape of the seasonal cycle in $T_{2 \mathrm{~m}}$ between San Francisco and Bergen highlights that continentality is not the only control of the seasonal phasing of $T_{2 \mathrm{~m}}$. The phasings of $T_{2 \mathrm{~m}}$ in Europe and North America differ due to the contrasting seasonality of cloud cover-specifically, the persistent summer stratus decks on the West Coast of the United States, which have no counterpart in western Europe. Additionally, the seasonal phasing of $T_{2 \mathrm{~m}}$ is influenced by the contrasting seasonal migration of the Atlantic and Pacific storm tracks: the Pacific storm track is centered on Alaska while Bergen is stormy throughout the year.

We note that the substantial differences evident in the time series highlighted in Figs. 7a and 7c correspond to modest values of ASYM $(-20$ days for the maritime record, +12 days for the continental record, +44 days for 
the North American record, and -1 day for the European record). These examples of contrasting seasonal shapes are not extreme cases; they are representative of differences in the shape of the seasonal cycle encapsulated by the amplitude of large-scale patterns of ASYM seen across the globe. Some of these points have been made previously at the local scale (van den Broeke 1998) and noted briefly in station data on a global scale (May et al. 1992) but the present work provides a comprehensive global analysis of ASYM based on both reanalysis and station data and extending throughout the troposphere. Much physical insight has been gleaned from analysis of the phase and amplitude of the annual harmonic in $T_{2 \mathrm{~m}}$ that has provided insights that are both fundamental and applicable to the long-term climate processes (i.e., climate feedbacks) relevant to global warming. We hope that the analysis of ASYM presented here will inspire future work probing the underlying physics that will lead to new insights relevant for large-scale processes at climate time scales.

We have identified in sections 4 and 5 several candidate mechanisms that explain the spatial pattern of ASYM seen in various locations including the atmospheric versus oceanic contrast in seasonal boundary layer depth in response to solar heating, the phase differences in surface solar radiation and top of atmosphere insolation due to clouds, and the impact of seasonal evolving atmospheric circulations such as the monsoon and stationary waves. This list is by no means exhaustive and we find no single mechanism that adequately explains the broad-scale features of ASYM.

We emphasize that much of our analysis is exploratory. In future work we hope to evaluate if ASYM is realistically simulated in comprehensive models and in a hierarchy of lower-complexity models (i.e., uncoupled, slab ocean, simplified radiative code, singlecolumn models) to isolate the fundamental processes responsible for ASYM (and its spatial variability). An observational pathway forward would be to analyze whether the phasing of the diurnal cycle varies seasonally in the same sense of ASYM. This result would suggest that single-column energetics associated with the atmospheric depth over which surface heating is communicated is an essential component in determining ASYM (and its spatial variability).

Acknowledgments. We thank Duo Chan for providing ocean weather ship data and Robert Hahn and Dennis D'Amico for assistance with Camp Muir temperature data. AD's work was partially funded by the NSF Antarctic Program Grant PLR 1643436.
Data availability statement: All data used in this work are publicly available through the Global Historical Climatology Network, European Centre for Medium-Range Weather Forecasts, National Centers for Environmental Prediction, and the National Aeronautics and Space Administration Langley Research Center websites. Please see citations within the data and methods section of this manuscript for more information.

\section{APPENDIX}

\section{Supplemental Analyses}

Six supplemental figures to support the findings of the main text are shown in this appendix. Figure A1 shows a global comparison of ASYM calculated from station data (abscissa) versus that calculated from the nearestneighbor ERA data. Figure A2 shows the same analysis of the seasonal timing of $T_{2 \mathrm{~m}}$ presented in Fig. 2 using the NCEP reanalysis 2-m air temperature instead of the ERA-Interim data. Figure A3 compares the seasonal cycle of $T_{2 \mathrm{~m}}$ at various altitudes in the Seattle area using high-elevation weather stations on Mount Rainier to probe the strong vertical gradients in $\tau_{\mathrm{MIN}}$ ) seen in Figs. 3 and 4.

In Fig. A4 we present an explanation for the curious sharp west-east gradient in $\tau_{\text {MIN }}$ over the ocean south of Australia in both reanalysis products (Figs. 2 and A2); $\tau_{\mathrm{MIN}}$ values to the west of Australia are typically $>70$ days whereas those to the east are $\sim 20$ days. This is an artifact, however. Throughout the region there is a 100-day period where temperature is very close to the seasonal minimum with a slight warming $(\sim 0.1 \mathrm{~K})$ in the middle of this period (see Fig. A4) resulting in two local

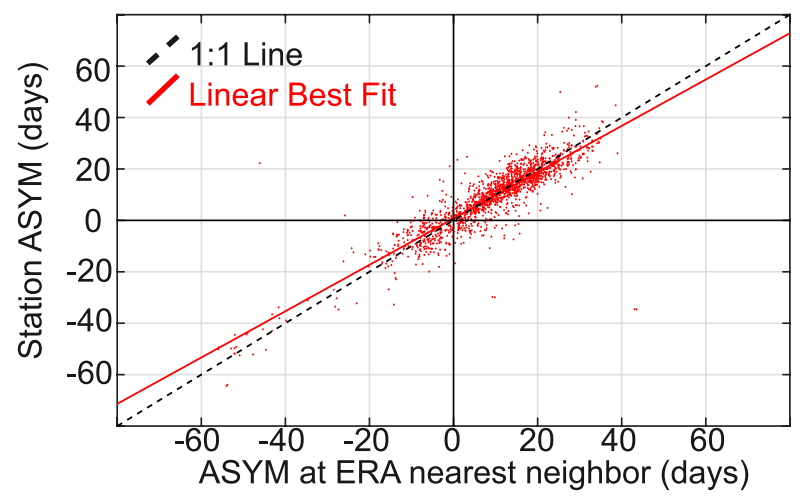

FIG. A1. Scatterplot of ASYM calculated from the station data (ordinate) vs the ASYM calculated from the ERA $T_{2 \mathrm{~m}}$ at the nearest grid point (abscissa). The dashed black line is the 1:1 line and the red line is the linear best fit. 

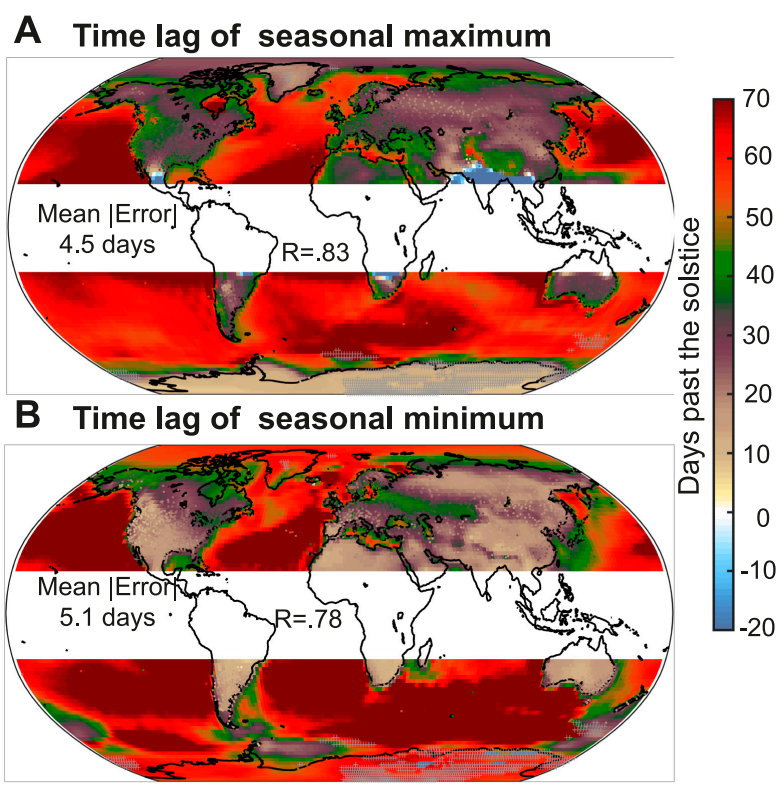

C Asymmetry of Seasonal Time lag (A-B)

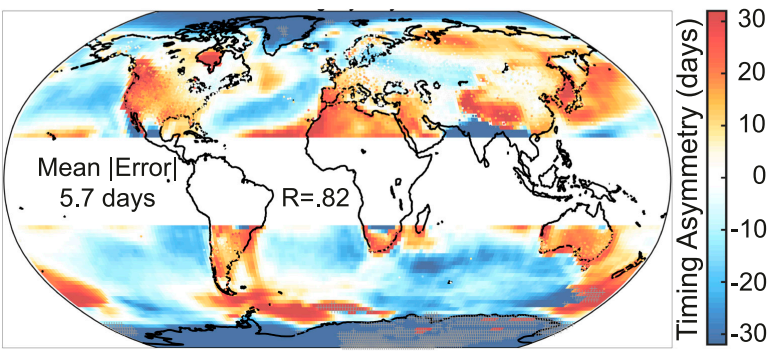

FIG. A2. As in Fig. 2, but for the NCEP reanalysis. (a) Time lag of seasonal maximum temperature relative to the summer solstice. Colors show results from the gridded $2-\mathrm{m}$ air temperature from the NCEP reanalysis and the individual dots show the locations of the station data color coded by the time lag given by the common color bar in the upper right. (b) As in (a), but for the time lag of the minimum temperature relative to the winter solstice. (c) The asymmetry in the timing of the seasons (ASYM), defined as (a) minus (b). This panel uses the color bar in the lower right. The gray stippling indicates regions with more than one temporal maxima and minima in the smoothed seasonal cycle of $T_{2 \mathrm{~m}}$.

temporal minima of $T_{2 \mathrm{~m}}$ at locations throughout the region. East (west) of Australia, the absolute minimum temperature occurs early (late) in this 100-day interval. (The minor local maximum in the middle of this 100-day interval is likely due to seasonal variations in upwelling.) We view this spatial discontinuity of $\tau_{\text {MIN }}$ as a shortcoming of the methodology used here to characterize the seasonal cycle of $T_{2 \mathrm{~m}}$, which was intended to represent a seasonal cycle with only one maximum and minimum.

Figure A5 compares the phasing of DSR calculated at stations in the United States to that calculated at

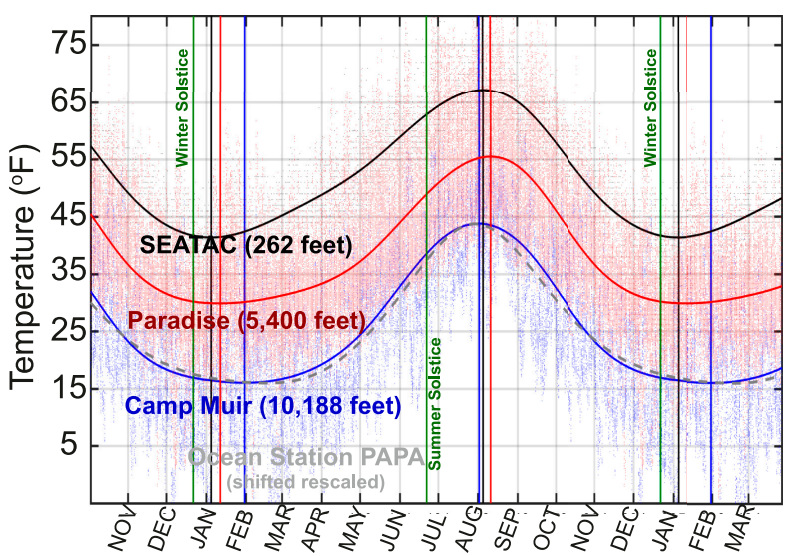

FIG. A3. Comparison of seasonal cycles of temperature on Mount Rainier at Paradise (elevation: 5400 feet, or $\sim 1645 \mathrm{~m}$; red) and Camp Muir (elevation: 10188 feet, or $\sim 3105 \mathrm{~m}$; blue) with that near sea level at SEATAC (black). The gray dashed line is the seasonal cycle of SST at ocean station Papa shifted and rescaled for visual comparison. The vertical lines indicate the timing of $\tau_{\text {MAX }}$ and $\tau_{\text {MIN }}$ in each time series given by the same color.

the nearest-neighbor gridpoint from the CERES data. Station data confirm the positive $\mathrm{RAD}_{\text {ASYM }}$ values seen in the northern latitudes of the United States extending from the Pacific coast to the midwest and the negative RADASYM values seen in southwest region (influenced by the North America monsoon), the southeast (i.e., Florida), and in Alaska. Figure A6 shows the change in downwelling solar radiation associated with the onset of the Indian monsoon.

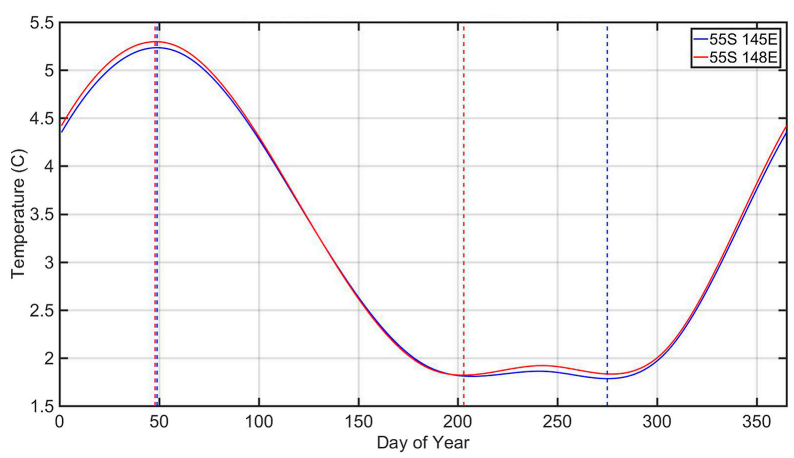

FIG. A4. Time series of ERA surface air temperature at grid points separated by $3^{\circ}$ longitude spanning the discontinuity in ASYM south of Australia seen in Fig. $2 \mathrm{c}$ at $55^{\circ} \mathrm{S}$. The blue time series is from $55^{\circ} \mathrm{S}, 145^{\circ} \mathrm{E}$ with ASYM $=-44$ days and the red time series is from $55^{\circ} \mathrm{S}, 148^{\circ} \mathrm{E}$ with ASYM $=+27$ days. The dashed vertical lines show the timing of $\tau_{\mathrm{MIN}}$ and $\tau_{\mathrm{MAX}}$ for the time series of the same color. 

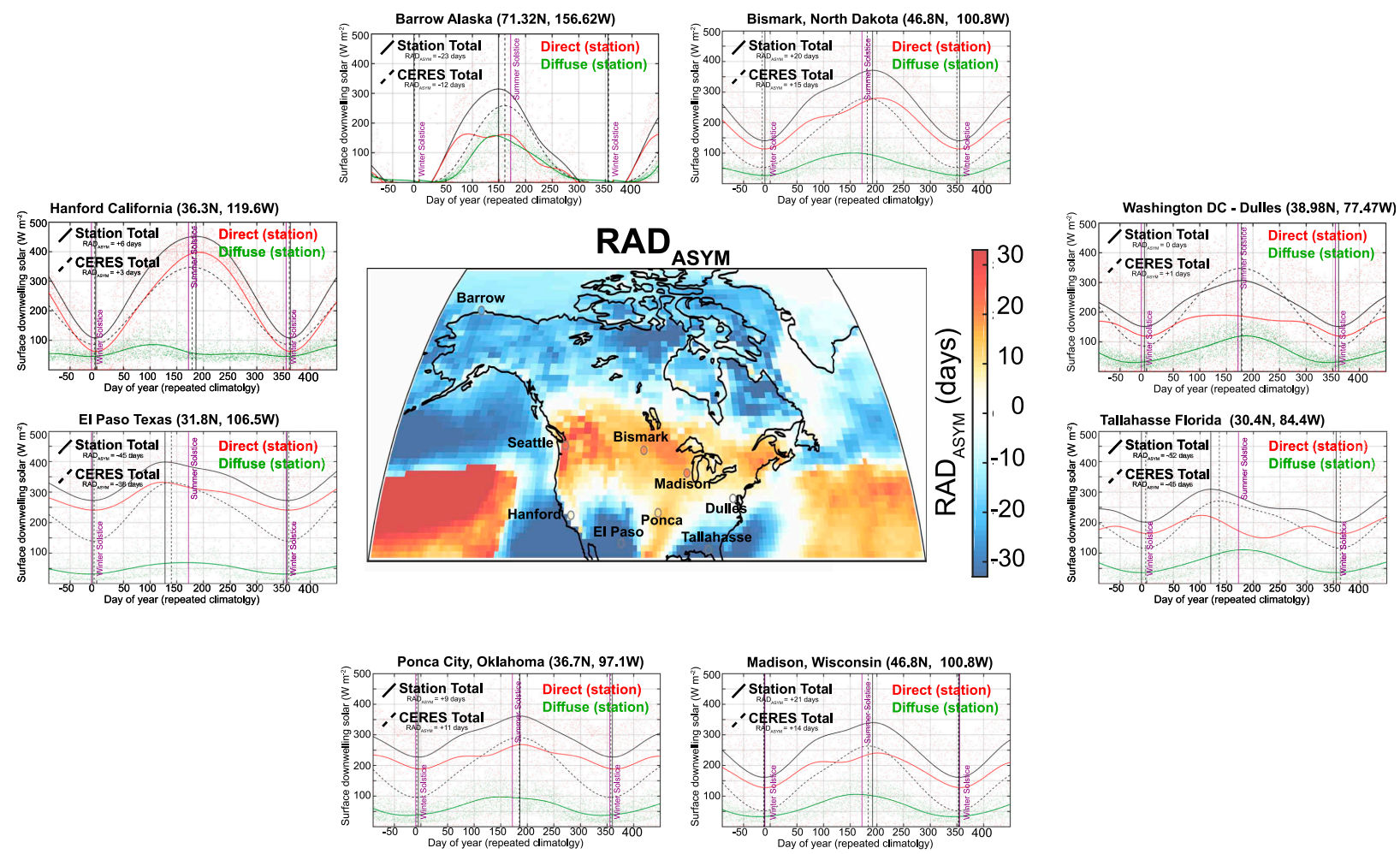

FIG. A5. Comparison of RAD $\mathrm{RAX}_{\text {, }} \mathrm{RAD}_{\mathrm{MIN}}$, and $\mathrm{RAD}_{\mathrm{ASYM}}$ calculated in the gridded CERES data to that calculated using DSR measurements from the United States (Sengupta et al. 2018). The dots show the observed daily mean DSR and the solid lines show the smoothed climatological seasonal cycle. The direct radiation is shown in red, the diffuse in green, and the total observed DSR in black. The dashed black line shows the smoothed seasonal cycle of total DSR from CERES data at the nearest-neighbor gridbox. Vertical lines show the time of RAD MAX and RAD ${ }_{\text {MIN }}$ identified in the smoothed time series of the same line type. The purple vertical lines show the winter and summer solstices. The inset map shows the RAD ASYM $_{\text {values at }}$

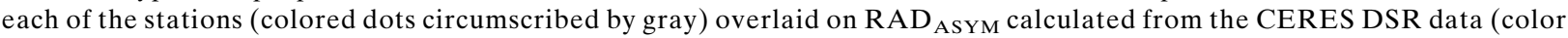
shading).

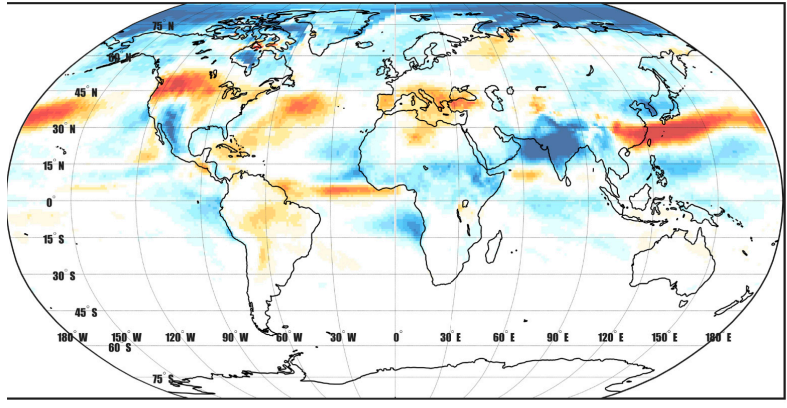

July minus June surface

downwelling solar radiation $\left(\mathrm{W} \mathrm{m}^{-2}\right)$

$\begin{array}{lllllll}-60 & -40 & -20 & 0 & 20 & 40 & 60\end{array}$

FIG. A6. Change in surface solar radiation associated with monsoon onset. The change is calculated as the difference in temporally smoothed (spline with $10 \mathrm{kt}$ ) downwelling solar radiation at the surface between $10 \mathrm{Jul}$ (just after summer solstice) and 1 Jun (20 days prior to summer solstice) from CERES data.

\section{REFERENCES}

Barnes, E., and I. Simpson, 2017: Seasonal sensitivity of the Northern Hemisphere jet streams to Arctic temperatures on subseasonal time scales. J. Climate, 30, 10117-10137, https:// doi.org/10.1175/JCLI-D-17-0299.1.

Belka, D., M. Schwendeman, J. Thomson, and M. Cronin, 2014: Historical wave and wind observations at Ocean Station P. APL-UW Tech. Rep. APL-UW 1407, 17 pp., http://www.apl. washington.edu/research/downloads/publications/tr_1407.pdf.

Berger, A., 1978: Long-term variations of caloric insolation resulting from the earth's orbital element. Quat. Res., 9, 139-167, https://doi.org/10.1016/0033-5894(78)90064-9.

Brooks, C., 1917: Continentality and temperature. Quart. J. Roy. Meteor. Soc., 43, 159-174, https://doi.org/10.1002/qj.49704318204.

Crowley, T., and G. North, 1988: Abrupt climate change and extinction events in Earth history. Science, 240, 996-1002, https:// doi.org/10.1126/science.240.4855.996.

D'Amico, D., 2019: Camp Muir weather data. Northwest Avalanche Center, https://www.nwac.us/weatherdata/paradise/now/.

de Boyer Montégut, C., G. Madec, A. Fischer, A. Lazar, and D. Ludicone, 2004: Mixed layer depth over the global ocean: 
An examination of profile data and a profile-based climatology. J. Geophys. Res., 109, C12003, https://doi.org/10.1029/ 2004JC002378.

Dee, D., and Coauthors, 2011: The ERA-Interim reanalysis: Configuration and performance of the data assimilation system. Quart. J. Roy. Meteor. Soc., 137, 553-597, https://doi.org/ 10.1002/qj.828.

Dodds, P. S., L. Mitchell, A. J. Reagan, and C. M. Danforth, 2016: Tracking climate change through the spatiotemporal dynamics of the teletherms, the statistically hottest and coldest days of the year. PLOS ONE, 11, e0154184, https://doi.org/10.1371/ journal.pone.0154184.

Donohoe, A., and D. Battisti, 2011: Atmospheric and surface contributions to planetary albedo. J. Climate, 24, 4402-4418, https://doi.org/10.1175/2011JCLI3946.1.

$\longrightarrow$, and — 2013: The seasonal cycle of atmospheric heating and temperature. J. Climate, 26, 4962-4980, https://doi.org/ 10.1175/JCLI-D-12-00713.1.

- D. Frierson, and D. Battisti, 2014: The effect of ocean mixed layer depth on climate in slab ocean aquaplanet experiments. Climate Dyn., 43, 1041-1055, https://doi.org/10.1007/s00382-013-1843-4.

Downes, C., 1977: History of the British ocean weather ships. Mar. Obs., XLVII, 179-186.

Dwyer, J., M. Biasutti, and A. Sobel, 2012: Projected changes in the seasonal cycle of surface temperature. J. Climate, 25, 63596374, https://doi.org/10.1175/JCLI-D-11-00741.1.

Eliassen, A., and E. Palm, 1961: On the transfer of energy in staionary mountain waves. Geofys. Publ., 22 (5), 1-23.

Gadgil, S., 2003: The Indian monsoon and its variability. Annu. Rev. Earth Planet. Sci., 31, 429-467, https://doi.org/10.1146/ annurev.earth.31.100901.141251.

Hasselmann, K., 1976: Stochastic climate models. Part I. Theory. Tellus, 28, 473-485, https://doi.org/10.3402/tellusa.v28i6.11316.

Held, I., M. Ting, and H. Wang, 2002: Northern winter stationary waves: Theory and modeling. J. Climate, 15, 2125-2144, https:// doi.org/10.1175/1520-0442(2002)015<2125:NWSWTA > 2.0.CO;2.

Holmes, T., W. Crow, and C. Hain, 2013: Spatial patterns in the timing of the diurnal temperature cycle. Hydrol. Earth Syst. Sci., 17, 3695-3706, https://doi.org/10.5194/hess-17-3695-2013.

Hurley, J., and W. Boos, 2015: A global climatology of monsoon low-pressure systems. Quart. J. Roy. Meteor. Soc., 141, 10491064, https://doi.org/10.1002/qj.2447.

India Meteorological Department, 2019: Onset and advance map of monsoon. Accessed 30 August 2019, https://mausam.imd. gov.in/imd_latest/contents/monsoon.php.

Kato, S., and Coauthors, 2018: Surface irradiances of Edition 4.0 Clouds and the Earth's Radiant Energy System (CERES) Energy Balanced and Filled (EBAF) data product. J. Climate, 31, 4501-4527, https://doi.org/10.1175/JCLI-D-17-0523.1.

Krishnamurthy, V., and J. Shukla, 2000: Intraseasonal and interannual variability of rainfall over India. J. Climate, 13, 4366-4377, https:// doi.org/10.1175/1520-0442(2000)013<0001:IAIVOR >2.0.CO;2.

Laepple T., and G. Lohmann, 2009: Seasonal cycle as template for climate variability on astronomical timescales. Paleoceanogr. Paleoclimatol., 24, PA4201, https://doi.org/10.1029/2008PA001674.

Loeb, N. G., and Coauthors, 2018: Clouds and the Earth's Radiant Energy System (CERES) Energy Balanced and Filled (EBAF) top-of-atmosphere (TOA) edition-4.0 data product. J. Climate, 31, 895-918, https://doi.org/10.1175/ JCLI-D-17-0208.1.

May, W., D. Shea, and C. Madden, 1992: The annual variation of surface temperature over the world. NCAR Tech. Note NCAR/TN-372+STR, 134 pp.
McKinnon, K., A. Stine, and P. Huybers, 2013: The spatial structure of the annual cycle in surface temperature: Amplitude, phase and Lagrangian history. J. Climate, 26, 7852-7862, https://doi.org/10.1175/JCLI-D-13-00021.1.

Misra, V., and S. DiNapoli, 2014: The variability of the Southeast Asian summer monsoon. Int. J. Climatol., 34, 893-901, https:// doi.org/10.1002/joc.3735.

Nayak, H., K. Osuri, P. Sinha, R. Nadimpalli, U. Mohanty, F. Chen, M. Rajeevan, and D. Niyogi, 2018: High-resolution gridded soil moisture and soil temperature datasets for the Indian monsoon region. Sci. Data, 5, 180264, https://doi.org/10.1038/ sdata.2018.264.

North, G. R., and J. A. Coakley, 1978: Simple seasonal climate models. Meteor. Gidrol., 5, 26-32.

Peixoto, J., and A. Oort, 1992: Physics of Climate. AIP Press, 160 pp.

Peterson, T., and R. Vose, 1997: An overview of the Global Historical Climatology Network temperature database. Bull. Amer. Meteor. Soc., 78, 2837-2849, https://doi.org/10.1175/ 1520-0477(1997)078<2837:AOOTGH > 2.0.CO;2.

Prescott, J., and J. Collins, 1951: The lag of temperature behind solar radiation. Quart. J. Roy. Meteor. Soc., 77, 121-126, https://doi.org/10.1002/qj.49707733112.

Reynolds, R., T. Smith, C. Liu, D. Chelton, K. Casey, and M. Schlax, 2007: Daily high-resolution-blended analyses for sea surface temperature. J. Climate, 20, 5473-5496, https:// doi.org/10.1175/2007JCLI1824.1.

Santer, B., and Coauthors, 2018: Human influence on the seasonal cycle of tropospheric temeprature. Science, 361, eaas 8806 , https://doi.org/10.1126/science.aas8806.

Sengupta, M., Y. Xie, A. Lopez, A. Habte, G. Maclaurin, and J. Shelby, 2018: The National Solar Radiation Data Base (NSRDB). Renewable Sustain. Energy Rev., 89, 51-60, https:// doi.org/10.1016/j.rser.2018.03.003.

Shuman, C., K. Steffen, J. Box, and C. R. Stearns, 2001: A dozen years of temperature observations at the summit: Central Greenland automatic weather stations 1987-99. J. Appl. Meteor., 40, 741-753, https://doi.org/10.1175/1520-0450(2001) $040<0741$ :ADYOTO $>2.0 . \mathrm{CO} ; 2$.

Sikka, D., and S. Gadgil, 1980: On the maximum cloud zone and the ITCZ over Indian longitudes during the southwest monsoon. Mon. Wea. Rev., 108, 1840-1853, https:// doi.org/10.1175/1520-0493(1980)108<1840:OTMCZA $>$ 2.0.CO;2.

Singh, R., S. Dey, S. Tripathi, and V. Tare, 2004: Variability of aerosol parameters over Kanpur, northern India. $J$. Geophys. Res., 109, D23206, https://doi.org/10.1029/2004 JD004966.

Stine, A., and P. Huybers, 2012: Changes in the seasonal cycle of temperature and atmospheric circulation. J. Climate, 25, 73627380, https://doi.org/10.1175/JCLI-D-11-00470.1.

,-- , and I. Fung, 2009: Changes in the phase of the annual cycle of surface temperature. Nature, 457, 435-440, https:// doi.org/10.1038/nature07675.

Taylor, K., M. Crucifix, P. Braconnot, C. Hewitt, C. Doutriaux, A. Broccoli, J. Mitchell, and M. Webb, 2007: Estimating shortwave radiative forcing and response in climate models. J. Climate, 20, 2530-2543, https://doi.org/10.1175/JCLI4143.1.

Thomson, D., 1995: The seasons, global temperature, and precession. Science, 268, 59-68, https://doi.org/10.1126/ science.268.5207.59.

Trenberth, K. E., 1991: Storm tracks in the Southern Hemisphere. J. Atmos. Sci., 48, 2159-2178, https://doi.org/10.1175/15200469(1991)048<2159:STITSH>2.0.CO;2. 
U.S. Weather Bureau, 1977: Changes made in ocean projects. Wea. Bur. Topics, 10, 132.

van den Broeke, M., 1998: The semi-annual oscillation and Antarctic climate. Part 1: Influence on near surface temperatures (1957-79). Antarct. Sci., 10, 175-183, https://doi.org/ 10.1017/S0954102098000248.

Von Hann, J., 1903: Handbook of Climatology. MacMillan, 437 pp.

Wallace, C., and T. Osborn, 2002: Recent and future modulation of the annual cycle. Climate Res., 22, 1-11, https://doi.org/ $10.3354 / \mathrm{cr} 022001$.
Webster, P., V. Magaña, T. Palmer, J. Shukla, R. Tomas, M. Yanai, and T. Yasunari, 1998: Monsoons: Processes, predictability, and the prospects for prediction. J. Geophys. Res., 103, 14 45114 510, https://doi.org/10.1029/97JC02719.

World Meteorological Organization, 2011: Guide to Climatological Practices. WMO Publication, 117 pp.

Yasunari, T., 1979: Cloudiness fluctuations associated with the Northern Hemisphere summer monsoon. J. Meteor. Soc. Japan, 57, 227-242, https://doi.org/10.2151/jmsj1965. 57.3_227. 